Diana Luiza Marinho Brandão

Desvio de inativação do cromossomo $\mathrm{X}$ em mulheres brasileiras sem histórico familiar para deficiência intelectual ligada ao X

\title{
Brasília-DF
}

2015 
UNIVERSIDADE DE BRASÍLIA

INSTITUTO DE BIOLOGIA

PROGRAMA DE PÓS-GRADUAÇÃO EM BIOLOGIA ANIMAL

\section{Desvio de inativação do cromossomo $X$ em mulheres brasileiras sem histórico familiar para deficiência intelectual ligada ao $\mathbf{X}$}

Diana Luiza Marinho Brandão

Brasília

2015 
UNIVERSIDADE DE BRASÍLIA

INSTITUTO DE BIOLOGIA

PROGRAMA DE PÓS-GRADUAÇÃO EM BIOLOGIA ANIMAL

\section{Desvio de inativação do cromossomo $X$ em mulheres brasileiras sem histórico familiar para deficiência intelectual ligada ao $\mathrm{X}$}

Dissertação apresentada ao Programa de Pós-Graduação em Biologia Animal do Instituto de Biologia da Universidade de Brasília como requisito parcial para a obtenção do título de Mestre.

Aluna: Diana Luiza Marinho Brandão

Orientadora: Profa. Dra. Silviene Fabiana de Oliveira

Brasília, 2015 
Trabalho desenvolvido no Laboratório de Genética e Morfologia, no Laboratório de Genética da Faculdade de Medicina, ambos, da Universidade de Brasília (UNB) e no Laboratório de Ciências Genômicas e Biotecnologia Molecular da Universidade Católica de Brasília (UCB) com suporte financeiro do Conselho Nacional de Desenvolvimento Científico e Tecnológico (CNPq). 
Diana Luiza Marinho Brandão

\section{Desvio de inativação do cromossomo $X$ em mulheres brasileiras sem histórico familiar para deficiência intelectual ligada ao $\mathbf{X}$}

Profa. Dra. Silviene Fabiana de Oliveira

(Orientadora)

Prof. Dr. Aparecido Divino da Cruz

(Examinador Externo)

Profa. Dra. Juliana Forte Mazzeu de Araújo

(Examinador Externo)

Prof. Dr. César Koppe Grisólia

(Examinador Suplente) 
Aos meus queridos pais, pelo amor e paciência. Ao meu único irmão, Isaac, pela possibilidade de aprender a lidar com seu autismo diariamente. À minha madrinha por sempre apoiar meu crescimento. Ao meu parceiro Gustavo, por toda dedicação e compreensão em nossa relação. A todas as voluntárias participantes da pesquisa. E a todos que de alguma forma ajudaram neste projeto.Dedico. 


\section{AGRADECIMENTOS}

Primeiramente a Deus, por tudo que tem me ofertado e pela possibilidade de trabalhar com pessoas tão maravilhosas durante essa jornada.

À minha orientadora, Silviene Fabiana de Oliveira, por ter me recebido de braços abertos em seu laboratório desde o primeiro momento, pelos ensinamentos e pela parceria.

À banca examinadora: Dra. Juliana Forte Mazzeu de Araújo, Dr. Aparecido Divino da Cruz e Dr. César Koppe Grisólia pelas sugestões e contribuições acerca da nossa pesquisa.

À minha família: mãe, pai, irmão, madrinha, tia pelo carinho e compreensão sempre dedicados a mim, vocês estão eternamente no meu coração.

Ao meu parceiro Gustavo Eberle por toda delicadeza e amor que me trouxe durante essa fase da minha vida.

À equipe de Genética da Faculdade de Medicina, Doutora Íris, Doutora Mara, Aluísio, Pedro, Naiara, Polly por terem me recebido como uma amiga no laboratório.

À equipe de Genética da Biologia, Sabrina, Rafa, Marcela, Arthur, Ana, Harumy, Mariana, Camila pelos encontros, pelas conversas e pelas trocas de experiências.

Ao Claudiner e ao Raphael pela realização dos arrays em nossas amostras.

Ao Davi, técnico da Universidade Católica de Brasília, que sempre me recebeu com um sorriso no rosto e pronto para tirar minhas dúvidas.

À professora Élida Campos por ter me acompanhado durante a graduação e ter me apoiado nas minhas escolhas.

Ao professor Túlio Ferreira por me ensinar muito do que sei hoje, durante meus primeiros experimentos na época da graduação, e por ter tido paciência comigo.

À professora Aline Pic-Taylor, por sempre me motivar e desejar o meu melhor.

Ao Diego que me levou até seu pai, enfermeiro, o qual me apresentou várias mulheres que se tornariam mais tarde participantes da nossa pesquisa.

À minha amiga e enfermeira, Camila Hirata, por ter me acompanhado durante o recrutamento de várias mulheres no Hospital de Base de Brasília. 
À minha amiga e enfermeira, Cristiane Salviano, por ter me ajudado muito durante a coleta e entrevista de várias mulheres no meu trabalho, você foi primordial.

À minha amiga e colega de trabalho, professora Vanessa, por ter me ajudado, também, durante o recrutamento das mulheres participantes da pesquisa.

À minha amiga Cândida pelo apoio irrestrito durante a fase de recrutamento das mulheres participantes.

À minha amiga e parceira de bancada Ariadne, pelas nossas conversas, pelo apoio e pela parceria desde o início da nossa pesquisa.

À Dani, secretária da pós - graduação, por me ajudar sempre que eu tinha dificuldade com a papelada, e pela sua participação direta na pesquisa.

À Direção geral do Instituto de Biologia, em especial à Maria que aceitou participar da pesquisa e ainda me apresentou a outras mulheres que se tornaram participantes.

À professora Sueli Gomes, pela sua participação direta na pesquisa e pelos seus ensinamentos práticos.

Às minhas amigas, Thaís, Jaque, Vanessa, Marinez, Ana Luísa, Patrícia, que me deram apoio durante momentos mais difíceis e me forneceram a energia necessária para continuar nossos trabalhos.

Aos meus coordenadores e superiores no trabalho, Instituto Federal de Brasília, que concordaram com a nossa pesquisa e possibilitaram direta ou indiretamente para que ela se tornasse possível.

Ao CNPq, pelo suporte financeiro.

Por fim, agradeço sinceramente a todas as mulheres que aceitaram o convite para participarem do estudo e contribuiram para que o projeto tivesse seus objetivos alcançados. 


\section{Sumário}

Resumo

Abstract

1. Introdução

1

1.1. Inativação do cromossomo $X$

1.2. Inativação do cromossomo $X$ em eutérios

1.3. Desvio de inativação do cromossomo $X$

1.4. Escape de genes da inativação do cromossomo $X$

6

1.5. Deficiência intelectual ligada ao cromossomo $X$

2. Objetivos

3.1. População de estudo

3.2. Extração de DNA

3.3. Análise de Inativação do cromossomo $X$

3.4. Digestão do DNA

3.5. Amplificação do produto da digestão e eletroforese

em gel de agarose

3.6. Eletroforese Capilar

3.7. Cariótipo

16

3.8. Microarray

4. Resultados e Discussão 


\section{Sumário de Figuras}

Figura 1: Estágios de inativação do cromossomo X. O RNA do gene $X I S T$ atua recobrindo o cromossomo $\mathrm{X}$ inativado $(\mathrm{Xi})$ e não é expresso pelo cromossomo $\mathrm{X}$ ativo $(\mathrm{Xa})$.

Figura 2: Demonstração de dois possíveis processos de inativação do

cromossomo X: o aleatório (50:50) e o não aleatório (100:0).

Figura 3: Localização das bandas cromossômicas onde se localizou mutações de genes causadores de Síndromes ligadas ao cromossomo X (Lubs et al, 2012).

Figura 4. Distribuição, em porcentagem, da autoclassificação fenotípica das 22 mulheres participantes.

Figura 5. Distribuição, em porcentagem, dos locais de nascimento das mulheres participantes da amostra.

Figura 6. A. Picos de amplificação dos dois alelos antes do tratamento com

enzima a Hha I; B. Pico de amplificação de apenas um alelo após o tratamento enzimático. Resultado de desvio total de inativação do cromossomo X, ou seja, existe preferencialmente a inativação de um dos cromossomos $\mathrm{X}$.

Figura 7. A. Resultado da amplificação da amostra sem o tratamento enzimático; B. Resultado da amplificação da amostra após o tratamento enzimático. Percebe-se que há semelhança entre os picos das duas reações.

Figura 8. A. Amostra controle, masculina, que não sofreu tratamento

enzimático; B. Amostra controle, masculina, após tratamento enzimático. Percebe-se que não houve amplificação significativa da amostra, uma vez que o único cromossomo X no homem encontra-se ativo e deverá ser digerido

Figura 9. Resultado normal da análise cromossômica representado pelo ideograma da amostra X53, não há descrição de CNVs patogênicas, entretanto foi identificada nesta amostra uma deleção localizada em X: 64,573,287$64,717,718$. 
Figura 10. Resultado da deleção no cromossomo X: 64,573,287-64,717,718. A faixa azul representa a duplicação, a faixa vermelha indica a deleção e a faixa cinza representa inversão. Observa-se que a deleção do gene inclui dois primeiros êxons indicados pela cor rosa.

Figura 11, 12 e 13. Ideogramas dos resultados normais para as outras três amostras: X60, X84 e X99, respectivamente, as quais apresentaram desvio total de inativação do cromossomo $\mathrm{X}$. 


\section{Sumário de tabelas}

Tabela 1. Comparação da autoclassificação fenotípica entre a amostra pesquisada e os dados do IBGE.

Tabela 2. Resultado do Padrão de Inativação do Cromossomo X (Razão de inativação do X), idade, idade de menarca e relato de câncer na família em amostra de população brasileira sem histórico familiar para deficiência intelectual e ou autismo.

Tabela 3. Resultado dos padrões de inativação do cromossomo X das mulheres estudadas.

Tabela 4. Dados coletados em entrevista para as quatro mulheres que apresentaram desvio total de inativação do cromossomo X. 


\section{Resumo}

A inativação do cromossomo $\mathrm{X}$ é um fenômeno biológico que ocorre exclusivamente em fêmeas durante os primeiros estágios embrionários de células de mamíferos. Esse fenômeno é consequência da compensação de dosagem dos produtos gênicos entre os sexos: masculino e feminino. Mulheres portadoras de mutações patogênicas presentes no cromossomo $\mathrm{X}$ podem apresentar o padrão desviado de inativação do cromossomo $\mathrm{X}$, que ocorre quando preferencialmente o cromossomo de mesma origem parental é inativado em ao menos $95 \%$ das células, favorecendo assim o alelo normal. Exemplo de mutações que podem alterar o padrão de inativação são genes situados no cromossomo X que estão correlacionados com a deficiência intelectual (DI). Neste projeto propôs-se determinar o perfil de inativação do cromossomo X em amostra de população brasileira que não apresentava histórico familiar para deficiência intelectual ligada ao X. A amostra foi constituída por 102 mulheres brasileiras, alfabetizadas. A maioria das mulheres participantes era nascida na Região Nordeste e Centro-Oeste e apresentou idade média de 46 anos. Os critérios de inclusão utilizados para a participação de todas as mulheres foram: idade mínima de 35 anos, ter tido pelo menos um filho biológico e não apresentar histórico familiar para deficiência intelectual ligada X. A análise do padrão diferencial de metilação do cromossomo X, utilizada para identificar a razão de inativação, revelou que quatro mulheres tinham desvio total de inativação do cromossomo $\mathrm{X}$. As quatro amostras com padrão desviado passaram pela análise de cariótipo, que se revelou normal para todos os casos, e pela técnica de análise cromossômica por microarranjos, que não identificou nenhum microrrearanjo patológico nas quatro amostras. Contudo, ao buscar associação entre informações obtidas durante as entrevistas com as participantes e o padrão desviado de inativação do $\mathrm{X}$, observou-se que três das quatro mulheres apresentavam também histórico familiar para câncer. Esse tipo de achado, previamente observado em tumores, pode servir de subsídios para que novas pesquisas busquem identificar quais os tipos de associação entre o fenômeno aqui estudado e a incidência de casos de câncer. 


\begin{abstract}
The chromosome $\mathrm{X}$ inactivation is a biological phenomenon, which occurs solely in cells of female mammals during their first embrionary stages. This phenomenon is consequence of the gene expression balancing of male and female gene. Women who have pathogenic mutations in the chromosome $\mathrm{X}$ can exhibit a skewed pattern of inactivation, which take place mainly when the chromosomes of the same parental origin is silenced in at least $95 \%$ of the body cells. Pathogenic mutations in genes located in the chromosome $\mathrm{X}$ has proved to play a pivotal role on the creating intellectual disabilities(ID), which are more frequently found in men rather than women. In this thesis we aim to establish the profile of inactivation of the chromosome $\mathrm{X}$ from a sample of the Brazilian population with no reported family background of X-linked mental impairment. The sample was compound by 102 Brazilian women. They were all literate and had severous occupations. Most of participants were born in Northeastern and Central-Western parts of Brazil, and showed average age of 46 years old. The criteria used for the selection of the sample was: woman, above 35 years old, having had at least one biological health male child; and who had any family record of Xlinked mental impairment. The study of the differential partner of methylation in the chromosome $\mathrm{X}$, intended to identify the inactivation ratio, unveiled that four women had skewed X-inactivation. All four divergent samples undergone karyotype analysis (normal for all cases) and microarray. No pathological micro-rearrangement was found. However, looking for association between information accessed by interview and skewed X-chromossome it was observed that three of the four women had family background of cancer. Findings such as this, previously reported in tumors, provides a basis for further researches to establish correlations between the phenomenon described herein and the incidence of certain types of cancer.
\end{abstract}




\section{INTRODUÇÃO}

\subsection{A inativação do cromossomo $X$}

A classe Mammalia é dividida em três subclasses, Prototheria (Monotremados), Metatheria (Marsupiais) e Eutheria, neste último grupo estão contidos os chamados mamíferos placentários. Os eutérios apresentam um sistema simples de determinação do sexo, contendo um par de alossomos do tipo $\mathrm{X}$ e $\mathrm{Y}$, sendo os machos heterogaméticos (XY). O cromossomo X contém aproximadamente 1155 genes; destes, cerca de 870 podem codificar proteínas (Ensembl, 2011). Como mecanismo compensatório entre os sexos, existe a inativação aleatória de um dos cromossomos $\mathrm{X}$ nas fêmeas ainda no período embrionário. Dessa forma, apenas uma cópia do cromossomo X encontra-se completamente ativa em indivíduos de ambos os sexos. Os mamíferos marsupiais apresentam um padrão de inativação do cromossomo X (ICX) mediado por imprinting, como consequência, nas fêmeas de cangurus acontece preferencialmente a inativação do cromossomo X de origem paterna (Sharman, 1971).

Em oposição aos mamíferos marsupiais, os cromossomos $\mathrm{X}$ de origem materna ou paterna são inativados com igual probabilidade nas células adultas das fêmeas eutérias. Assim, acredita-se que metade das células expressam genes do cromossomo X paterno e a outra metade genes do cromossomo X materno. A inativação aleatória nos eutérios apresenta as seguintes etapas: contagem do número de cromossomos $\mathrm{X}$ por genoma diplóide, escolha de um cromossomo X para ser inativado, propagação do estado inativado e sua manutenção para as novas gerações celulares (Escamilla-Del-Arenal, 2011).

A primeira vez que uma estrutura no núcleo de neurônios de gatas foi visualizada, ela recebeu a denominação de "satélite nucleolar" e hoje é mais conhecida como corpúsculo de Barr ou cromatina sexual (Barr, 1949). Cogitou-se que tal estrutura estaria ligada a carcinomas mamários. Mais tarde, pôde ser observado que essa estrutura era um cromossomo sexual presente nas fêmeas de camundongos, dessa maneira ficou marcada uma característica de base citológica para o dimorfismo sexual entre mamíferos, a qual lida com a presença da cromatina sexual (Ohno, 1960).

Estudos posteriores com fenótipos em mosaico de genes ligados a cor da pelagem de camundongos presentes no cromossomo $\mathrm{X}$ trouxeram à tona $\mathrm{o}$ fenômeno biológico 
da inativação do cromossomo X, sendo notado apenas em fêmeas (Lyon, 1961). Dessa forma, as principais contribuições para o melhor entendimento desse processo apontaram:

- O corpúsculo de Barr é um dos cromossomos X das fêmeas de mamíferos que permanece inativo nas células somáticas.

- O processo de inativação do cromossomo X é disparado durante os primeiros estágios do desenvolvimento embrionário.

- A inativação do cromossomo X ocorre de maneira aleatória, ora promovida com o Xp (X de origem paterna), ora com o Xm (X de origem materna).

A evolução dos cromossomos sexuais teria ocorrido a partir de um par de cromossomos autossomos. O gene SRY (sex-determining region $\mathrm{Y}$ ) advindo de um homólogo desse par (proto-Y) desencadeou ao longo da evolução a perda de segmentos do proto-Y, fato este que impediu a recombinação entre proto-Y e proto-X (Ohno, 1969). A partir desse isolamento de recombinação houve um estágio de "erosão" do cromossomo $\mathrm{Y}$, quando diversas regiões genômicas foram perdidas, o que levou a diferenciação entre cromossomos sexuais X e Y. A inativação do cromossomo X nas fêmeas confirma o mecanismo para compensação dos produtos gênicos entre os diferentes cromossomos sexuais. Em situações específicas foi observado que não existe um padrão aleatório de inativação, mas sim o favorecimento do cromossomo de mesma origem. Por exemplo, em tecidos extraembrionários de murinos observa-se a inativação preferencial do cromossomo X de origem paterna (Wake, 1976).

Estudos que buscam melhor entender a inativação do cromossomo $\mathrm{X}$ no estágio embrionário de humanos apresentam dificuldades técnicas, o que envolve desde as leis sobre o uso de embriões humanos e a qualidade das amostras ofertadas para tal finalidade, dentre outras questões. Um estudo com embriões humanos em estágio préimplantação demonstrou não haver evidências do início da inativação do cromossomo X nessa fase (Okamoto, 2011). 


\subsection{Inativação do cromossomo $X$ em eutérios}

A inativação aleatória do cromossomo $\mathrm{X}$ nos eutérios é controlada pelo centro de inativação do cromossomo X (CIX) e pelo gene XIST (Transcrito específico para inativação do X), o qual não foi detectado nos monotremados ou nos marsupiais (Escamilla-Del-Arena, 2011). O gene XIST inicia a inativação e a propagação do estado inativado, enquanto outros elementos do centro de inativação agem sobre a contagem de cromossomos $\mathrm{X}$ e a escolha dos cromossomos que serão inativados (Shevchenko, 2013). A inativação do cromossomo $X$ pode ser revelada no núcleo interfásico feminino por meio de técnicas citológicas, as quais apontam uma massa compacta de cromatina, o corpúsculo de Barr.

O DNA dependente de RNA polimerase II, responsável pela transcrição celular, é quase completamente eliminado do cromossomo inativo na intérfase nuclear. $O$ cromossomo $\mathrm{X}$ inativo é lentamente replicado, e migra para a região perinuclear, a qual é rica em enzimas importantes na produção da estrutura inativa do cromossomo. O RNA do gene XIST é enriquecido em repetições do tipo microsatélite, as quais atuam como domínios requeridos para repressão da transcrição, propagação do cromossomo $\mathrm{X}$ inativo e ligantes de complexos protéicos responsáveis pelas modificações na cromatina. O transcrito do gene XIST se acumula no cromossomo X que será inativado (Xi) pelo padrão in cis, como está indicado na Figura 1. 


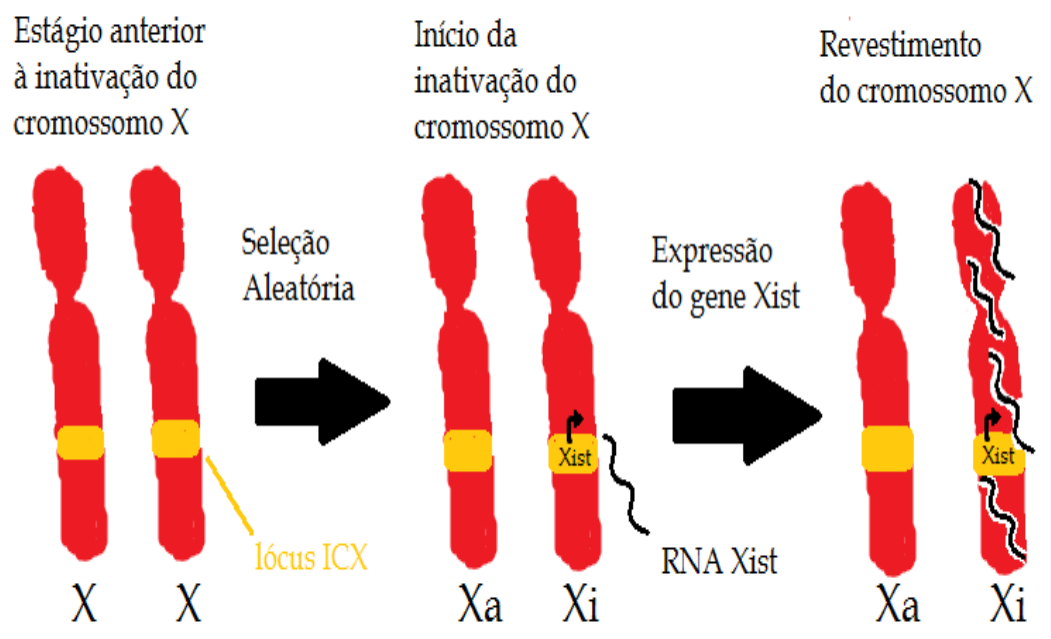

Figura 1: Estágios de inativação do cromossomo X. O RNA do gene XIST atua recobrindo o cromossomo $\mathrm{X}$ inativado $(\mathrm{Xi})$ e não é expresso pelo cromossomo $\mathrm{X}$ ativo (Xa).

Nos humanos, foi identificado um transcrito antissentido ao XIST, denominado TSIX, o qual atua como agente regulador sobre a expressão do gene XIST. TSIX não se sobrepõe completamente à sequência de XIST, fato esse que ocorre em camundongos. Outra peculiaridade desse agente regulador em humanos é que ele é expresso a partir do cromossomo $\mathrm{X}$ inativado (Xi) e atua na repressão do XIST para aquele cromossomo, o que permite o disparo das cascatas de eventos da inativação. A partir da escolha de qual cromossomo $\mathrm{X}$ deverá ser inativado, é iniciado o comando para o centro de inativação do cromossomo X e o gene XIST produz transcritos não codantes que se posicionam ao longo do próprio cromossomo, revelando sua atividade cis. Essa fase dará início as outras manifestações celulares epigenéticas necessárias para que a inativação ocorra. Tais manifestações epigenéticas incluem modificações de histonas, incorporação de diferentes tipos de histonas ao cromossomo a ser inativado, a metilação do DNA, além da compartimentalização do cromossomo. 
O DNA do cromossomo $\mathrm{X}$ inativado nos tecidos embrionários de mamíferos eutérios se encontra hipermetilado nas chamadas ilhas $\mathrm{CpG}$, localizadas em regiões promotoras e 5' não traduzidas dos genes, durante o processo de inativação (Hellman, 2007). A metilação não é detectável durante a inativação instável nos tecidos extraembrionários dos eutérios, nem nos tecidos somáticos dos marsupiais (Cooper, 1993). Além do mais, a metilação do DNA durante a inativação aleatória parece ter iniciado nos eutérios como um estágio adicional de estabilização do cromossomo $\mathrm{X}$ das células somáticas (Shevchenko, 2012).

Dessa maneira, a inativação do cromossomo X é aleatória e do tipo clonal, sendo que o centro de controle deste processo que inclui o gene XIST está presente no cromossomo X (Shevchenko, 2013).

\subsection{Desvio de inativação do cromossomo $X$}

Foi notado que a inativação não aleatória do cromossomo $\mathrm{X}$ pode ocorrer em mulheres portadoras de aberrações cromossômicas estruturais, como translocação X/autossomo, evitando-se assim, a inativação de genes autossômicos (Robinson, 2001). Vários distúrbios ligados ao cromossomo $\mathrm{X}$ têm sido associados a maior prevalência de padrões de inativação do cromossomo $X$ do tipo não aleatórios. Este desvio de inativação pode ocorrer também em portadoras de rearranjos submicroscópicos no cromossomo $\mathrm{X}$, ou ainda em portadoras de mutações de ponto com efeito patogênico (Augenstein, 2009; Froyen, 2007; Nascimento, 2006).

Portanto, acredita-se que nos casos que envolvam alterações estruturais ou de sequência do cromossomo $\mathrm{X}$, pode-se esperar a inativação preferencial do cromossomo alterado, proporcionando ao organismo uma seleção dirigida para preservar as funções celulares com a manutenção ativa do cromossomo X não afetado. Ainda, há evidências de que a penetrância da deficiência intelectual em mulheres portadoras de mutações ligadas ao cromossomo $\mathrm{X}$ pode estar associada ao desvio de inativação do cromossomo $\mathrm{X}$, apesar de, em geral, não existir avaliação dos perfis de inativação do cromossomo $\mathrm{X}$ dessas mulheres. 


\subsection{Escape de genes da inativação do cromossomo $X$}

Os perfis de escape de genes à inativação do cromossomo $\mathrm{X}$ em ratos e em humanos demonstraram uma significativa diferença entre o número de genes inativados, sendo o escape desses genes muito mais prevalente em humanos, por razões ainda desconhecidas (Zhang, 2013). As aneuploidias humanas que cursam com cromossomos $\mathrm{X}$ adicionais estão associadas com fenótipos distintos e heterogêneos, que incluem a deficiência intelectual e distúrbios de crescimento como sinais fenotípicos mais prevalentes (Rooman, 2012). Portanto, determinar quais são os genes que escapam da inativação do cromossomo X é considerado de relevante potencial clínico. O padrão de inativação do cromossomo $X$ é classificado como aleatório, quando há a relação $\leq 80 \%$ de um dos cromossomos $\mathrm{X}$ inativado e $20 \%$ do segundo cromossomo inativo; perfil moderadamente desviado se a proporção for entre 80:20 e 90:10, e altamente desviado para perfis >90:10 (Amos-Landgraf, 2006). Dois exemplos de padrões de inativação do cromossomo X podem ser vistos na Figura 2.

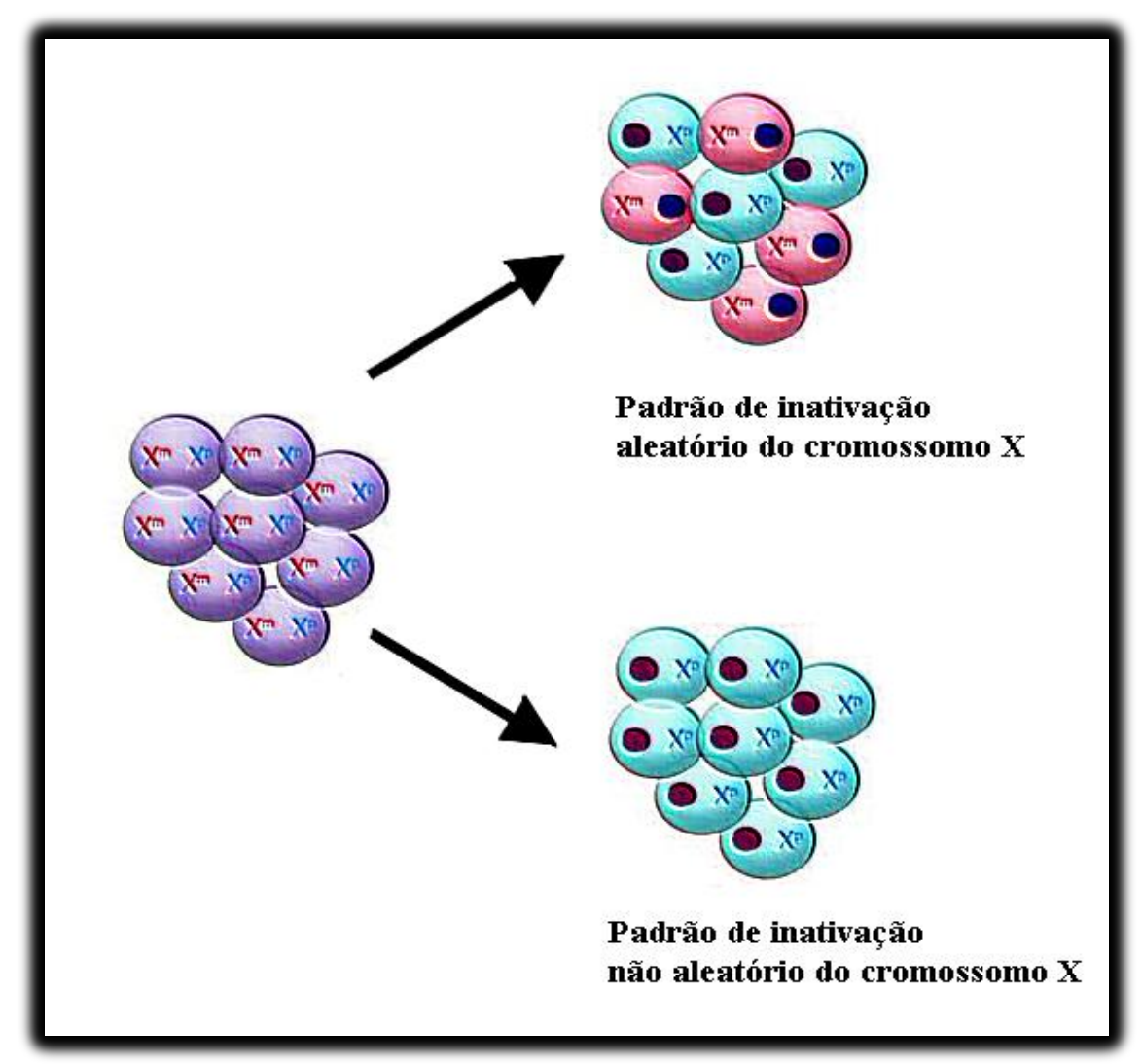

Figura 2: Demonstração de dois possíveis padrões de inativação do cromossomo X: o aleatório (50:50) e o não aleatório (100:0). 
Exemplos de desvios de inativação associados a condições clínicas podem ser observados na literatura. Dentre esses, há o relato de uma família mexicana com presença de anormalidades digitais, distúrbio intelectual leve a moderado e baixa estatura. O quadro clínico foi observado em homens. A avaliação do perfil de inativação do cromossomo $\mathrm{X}$ revelou que metade das mães apresentavam desvio de inativação do cromossomo $\mathrm{X}$ e a outra metade, inativação do tipo aleatório para o cromossomo $\mathrm{X}$ (Barboza, 2013). A avaliação de uma família chinesa com deficiência intelectual ligado ao cromossomo $\mathrm{X}$ apontou que uma mutação no gene $C U L A B$, o qual está intimamente ligado ao complexo de ubiquitinação, poderia ser a possível causa dessa condição para alguns indivíduos da família. Porém, outros indivíduos da família apresentaram desvio no perfil de inativação do cromossomo $\mathrm{X}$ e não apresentaram a mutação para $C U L A B$. Dessa forma, tanto para os indivíduos portadores como para os não afetados, os níveis de RNA $C U L A B$ se apresentam em elevadas concentrações, fato este que pode estar associado à presença do desvio de inativação do alelo mutato (Zouet, 2007).

Mutações no gene $U B E 2 A$ podem ocasionar desvio total de inativação do cromossomo $\mathrm{X}$, de acordo com o que foi demonstrado pelo estudo de famílias com distúrbio intelectual ligado ao $\mathrm{X}$ do tipo Nascimento. Esse distúrbio foi descrito em 2006 como sendo causado por uma mutação no gene UBE2A. Esta síndrome é caracterizada clinicamente por retardo grave do desenvolvimento psicomotor, face ampla, hipertelorismo, distúrbios urogenitais, entre outras características. Em uma pesquisa envolvendo oito pacientes de cinco famílias distintas, com suspeita para distúrbio intelectual do tipo Nascimento foi observado que existia mutação no gene $U B E 2 A$ em todos os pacientes do sexo masculino. As mães, assim como algumas avós e tias desses pacientes, que são assintomáticas para síndrome, foram testadas para análise do perfil de inativação e revelaram desvio total (100:0) de inativação do cromossomo X (CzeschiK, 2013). Os experimentos demonstraram que todas as mulheres portadoras da mutação apresentam desvio total de inativação do cromossomo.

Não apenas para estudo de deficiência intelectual ligada ao cromossomo X, mas também para outras patologias de grande impacto na saúde das populações, a análise do perfil de inativação do cromossomo $\mathrm{X}$ está sendo cada vez mais utilizada pelos pesquisadores. Em um estudo acerca do perfil de inativação do cromossomo X ocorrido com mulheres taiwanesas com diagnóstico de câncer de mama demonstrou-se que 
aproximadamente $23 \%$ do total dessas mulheres apresentavam desvio de inativação do cromossomo X no tecido tumoral, bem como em tecido sadio adjacente (Chen, 2014).

A incidência de desvio de inativação em mulheres dos Estados Unidos, Finlândia e Israel, tanto adultas como recém-nascidas, foi estimada em 8\% (AmosLandgraf, 2006). O único estudo brasileiro do gênero foi realizado no sudeste do Brasil com mães de meninos com deficiência intelectual, que relatou uma frequência de $11 \%$ de desvio total de inativação nessas mães (Coqueti, 2011). Estudo semelhante em nosso laboratório, realizado com mães de meninos deficientes intelectuais atendidos pelo serviço de Genética do Hospital Universitário de Brasília-HUB, demonstrou que dentre dezoito mães estudadas, uma apresentava desvio total de inativação do cromossomo $\mathrm{X}$, revelando a importância dessa análise.

Há vários genes, cujos produtos desempenham função neurológica, localizados no cromossomo X, que estão sendo estudados para melhor compreensão de seus papéis na capacidade cognitiva dos indivíduos (Zechner, 2001). Além disso, foi observado que a expressão de genes ligados ao $\mathrm{X}$ no cérebro é maior do que aquela notada em outros tecidos somáticos. Observa-se que deficência intelectual ligada ao cromossomo X é três a cinco vezes mais frequente do que formas autossômicas (Ropers, 2010; Skuse, 2005). Ainda, mutações em genes que escapam da inativação foram relacionadas a diversos tipos de câncer, como por exemplo a associação entre microdeleções do gene KDM6A e o desenvolvimento do câncer de próstata (Grasso, 2012; Van Haften, 2009). As mutações constitucionais do gene KDM6A também são apontadas como causais da Síndrome de Kabuki, a qual se caracteriza por anormalidades esqueléticas, baixa estatura e deficiência intelectual moderada a profunda (Miyake, 2012; Lederer, 2012).

\subsection{Deficiência intelectual ligada ao cromossomo $X$}

Deficiência intelectual ligada ao $\mathrm{X}$ é uma causa comum de déficit cognitivo herdado que afeta principalmente indivíduos do sexo masculino. Existem várias causas genéticas implicadas nesta condição, o que dificulta o estabelecimento de um diagnóstico preciso (Jorge, 2013). Estima-se que a deficiência intelectual ligada ao X (XLID) esteja presente entre $1 \%$ a $3 \%$ da população. A XLID inclui condições heterogêneas, as quais são marcadas por déficit cognitivo e reduzidas habilidades 
adaptativas. A Figura 3 indica regiões cromossômicas que contem genes descritos como associados ao XLID.
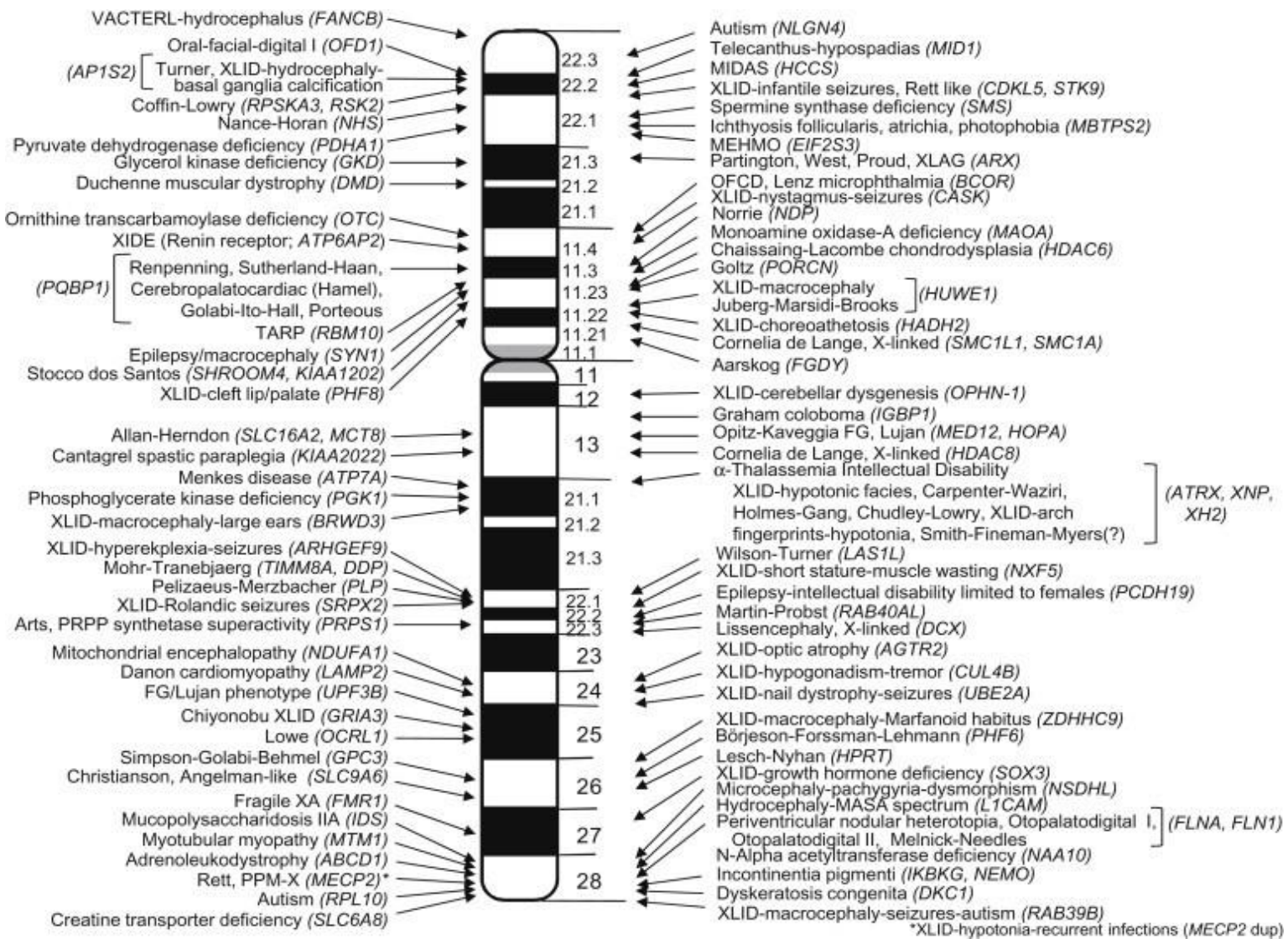

Figura 3: Ideograma do cromossomo X humano, indicando as bandas cromossômicas e mutações que foram associadas às síndromes que causam deficiência intelectual (Lubs, 2012).

Segundo a Organização Mundial da Saúde, a deficiência intelectual estabelecese antes dos 18 anos de idade, sendo assim uma doença do neurodesenvolvimento. A etiologia da deficiência intelectual é consequência da ação de fatores ambientais, genéticos, ou, ainda, a junção dos dois, o que revela seu caráter multifatorial. Dentre os fatores ambientais, durante a gestação, aparecem com maior prevalência os agravos decorrentes da exposição fetal a agentes químicos como o álcool, e/ou às drogas lícitas ou ilícitas, e a agentes biológicos, como no caso de rubéola e toxoplasmose. A deficiência intelectual também pode ser causada por problemas durante o parto, como a prematuridade e a dimunição da oferta de oxigênio ao cérebro do neonato. Como origem genética, apresentam-se as anomalias cromossômicas, como por exemplo, as 
deleções e duplicações, as quais afetam múltiplos genes, ainda, por mutação de um único gene, podendo apresentar caráter autossômico dominante ou recessivo, além de apresentar herança ligada ao cromossomo X (Tarpey, 2009).

O desenvolvimento de tecnologias que facilitam a detecção de microarranjos, isto é, microdeleções e microduplicações, vêm permitindo o aumento na descrição de regiões genômicas relacionadas às mais diversas patologias, incluindo a deficiência intelectual. Por exemplo, foi descrito que $10 \%$ de famílias européias e euroderivadas (australianas, dos Estados Unidos da América e da África do Sul) com segregação de deficiência mental ligada ao $\mathrm{X}$ apresentavam variação no número de cópias, o que possibilitou o relato de quatro genes adicionais ao conjunto de genes descritos para essa patologia (Whibley, 2010).

Diante da possível contribuição que o estudo do fenômeno biológico da inativação do cromossomo $\mathrm{X}$ em amostra de mulheres brasileiras sem histórico familiar para deficiência intelectual poderia trazer, além de tentar suprir a carência de conhecimento sobre a incidência de desvio total de inativação do cromossomo $\mathrm{X}$ na população brasileira, essa pesquisa pode ser utilizada para comparar amostras em que o histórico familiar para deficiência intelectual ligada ao X esteja presente. 


\section{OBJETIVO}

O objetivo geral deste projeto consistiu em avaliar a incidência de desvio de inativação do cromossomo $\mathrm{X}$ em um grupo de mulheres brasileiras sem histórico familiar para a deficiência intelectual e verificar a relação entre desvio de inativação e alterações estruturais cromossômicas.

Os objetivos específicos foram:

1- Analisar o padrão de inativação do cromossomo $\mathrm{X}$ de todas as mulheres participantes;

2- Realizar cariótipo das mulheres que apresentaram desvio de inativação;

3- Buscar microarranjos usando a técnica de análise cromossômica por microarray no genoma das mulheres com desvio de inativação do cromossomo X e com cariótipo normal;

4- Buscar ocorrência de associação entre dados levantados na entrevista e os resultados quanto à inativação do cromossomo X. 


\section{MATERIAL E MÉTODOS}

\subsection{População de estudo}

Para a análise da incidência de desvio de inativação do cromossomo $X$ da amostra foi utilizado material biológico (sangue) de 102 mulheres não afetadas por deficiência intelectual ligada ao $\mathrm{X}$ e/ou autismo e que não apresentavam casos desse tipo de condição na família. Os pré-requisitos para participação de todas as mulheres na pesquisa foram:

- idade mínima de 35 anos.

- ter tido, pelo menos, um filho (do sexo masculino).

- não apresentar histórico familiar de deficiência intelectual ligada ao X e/ou autismo.

Todo material biológico foi coletado em Brasília e região do entorno do Distrito Federal. As mulheres participantes foram devidamente informadas sobre os objetivos do estudo e puderam esclarecer suas dúvidas a respeito de qualquer etapa da pesquisa. Antes da coleta do sangue, realizada por profissional tecnicamente habilitado, todas as voluntárias da pesquisa assinaram o termo de consentimento livre e esclarecido (TCLE/Anexo 2) e responderam ao questionário (Anexo 1).

O recrutamento dessas mulheres ocorreu de maneira aleatória mediada por busca ativa, por meio de convites afixados em local de maior circulação de pessoas, como instituições educacionais. Houve, também, coletas programadas na forma de encontros, com alguns grupos de mulheres que aceitaram participar da pesquisa. A realização da coleta de material biológico e das entrevistas ocorreu nos locais de trabalho de algumas voluntárias, como o Hospital de Base do Distrito Federal (HBDF), Hospital Regional da Asa Norte (HRAN), e local de ensino, como o Instituto Federal Brasília (IFB), campus São Sebastião e campus Taguatinga Norte. Durante a realização dessas coletas externas houve sempre o acompanhamento de uma enfermeira ou de uma biomédica para 
assegurar todas as ações de biossegurança e de assepsia necessárias à coleta de amostras biológicas.

\subsection{Extração e isolamento de DNA}

A extração de DNA, a partir de sangue periférico foi feita pelo método "salting out" da Puregene. A primeira etapa deste método consistiu na lise celular a partir de $5 \mathrm{mM}$ de $\mathrm{MgCl}_{2}, 1 \mathrm{mM}$ de EDTA $\mathrm{pH} 8,0$ em uma reação e $10 \mathrm{mM}$ de Tris $\mathrm{pH} 7,5,1 \mathrm{mM}$ de EDTA pH 8,0 e 1\% SDS em outra reação. Após adicionar cada reação, a solução foi centrifugada a $3400 \mathrm{rpm}$ durante 10 minutos.

A etapa seguinte utilizou o lisado celular e a solução de precipitação de proteína, composta por 7,5M de acetato de amônio. A mistura foi centrifugada a $3400 \mathrm{rpm}$ por 10 minutos. Um pellet de cor escura e compacto foi formado a partir da precipitação das proteínas.

$\mathrm{Na}$ etapa de precipitação do DNA, o sobrenadante foi transferido para um tubo tipo Falcon contendo $3 \mathrm{~mL}$ de isopropanol. $\mathrm{O}$ tubo foi delicadamente invertido até que foi possível a visualização de DNA. A solução foi centrifugada a $3400 \mathrm{rpm}$ por 3 minutos. O sobrenadante foi retirado e acrescentou-se $3 \mathrm{~mL}$ de etanol absoluto. A reação foi novamente centrifugada. Logo após, retirou-se toda a fase líquida da solução, atentando para que o DNA ficasse no fundo do tubo, o qual foi deixado para secar a temperatura ambiente por 15 minutos. Acrescentou-se ao tubo com DNA cerca de 200$250 \mu \mathrm{L}$ de TE $1 \mathrm{X}$ e obteve-se ao final uma concentração aproximada de $400 \mathrm{ng} / \mu \mathrm{L}$ de DNA. O DNA foi armazenado entre $2-8^{\circ} \mathrm{C} . \mathrm{O}$ espectofotômetro utilizado para quantificar as amostras de DNA foi o aparelho Nanovue ${ }^{\circledR}$, o qual permite identificar a razão 260/280 nm para se avaliar a pureza da amostra. 


\subsection{Análise de Inativação do cromossomo $X$}

Para estudar a inativação do cromossomo $\mathrm{X}$ nas mulheres participantes do estudo, foi analisado um marcador genético do tipo microssatélite localizado no gene $A R$ (Androgen Receptor Gene; Xq11-12) que codifica para um receptor de andrógeno. Tal análise consistiu em verificar o padrão de metilação de uma repetição com sequência cerne CAG no gene $A R$ (Allen, 1992), pois a metilação ocorre apenas no locus do gene $A R$ do cromossomo $\mathrm{X}$ inativado. Esse gene apresenta um número variável de repetições $\mathrm{CAG}$ em seu éxon 1 e é sabido que próximo à região dessas repetições existe um sítio de corte para a enzima Hhal. Essa enzima digere apenas fragmentos de DNA não metilados. O teste consiste na amplificação da região por reação em cadeia da polimerase (PCR) e na análise do marcador genético na ausência e na presença da enzima HhaI. Dessa forma, a etapa sem digestão permitiu determinar os alelos presentes na mulher que, após a digestão, indicava a inativação preferencial de algum desses alelos e, consequentemente, de um dos cromossomos X. Como amostra controle, foi utilizada uma amostra de DNA de homem saudável. A amostra do sexo masculino possui o cromossomo $\mathrm{X}$ em hemizigose e, portanto, ele sempre está ativo, não metilado. Assim a enzima Hhal é capaz de digerir a sequência correspondente ao $A R$ e, consequentemente, os fragmentos gerados não poderão ser amplificados por PCR.

\subsection{Digestão do DNA}

Foram preparadas duas reações simultaneamente: 1) amostra de DNA preparada com a enzima HhaI, BSA, tampão e água, 2) amostra de DNA preparada com todos os reagentes participantes da digestão (água, tampão e BSA), exceto a enzima HhaI. Todas as reações foram conduzidas em um volume final de $20 \mu \mathrm{L}$ e foram incubadas a seco a uma temperatura de $37^{\circ} \mathrm{C}$ por 14 horas no termociclador (Allen,1992). 


\subsection{Amplificação do produto da digestão e eletroforese em gel de agarose}

O volume total de cada amostra submetida à PCR foi de $30 \mu \mathrm{L}$. Na preparação das amostras, usou-se $4 \mu \mathrm{L}$ de DNA digerido e não digerido separadamente, $15 \mathrm{pmol}$ de iniciadores forward e reverse, $1 \mathrm{u}$ de enzima Taq DNA polimerase (Invitrogem), $4 \mu \mathrm{L}$ de DNTP $200 \mu \mathrm{L}, 2,5 \mu \mathrm{L}$ de 10x PCR Buffer, 1,5 $\mu \mathrm{L}$ Dimethyl sulfoxide (DMSO). A termociclagem consistiu de: ciclo 1 . Desnaturação a $94^{\circ} \mathrm{C}$ por 1 minuto, anelamento a $69^{\circ} \mathrm{C}$ por 30 segundos e $72^{\circ} \mathrm{C}$ para a extensão; ciclo 2 a 13 : diminuição em $0,5^{\circ} \mathrm{C}$ na temperatura de anelamento a cada ciclo; ciclo 14 a 30: desnaturação a $94^{\circ} \mathrm{C}$, anelamento a $62^{\circ} \mathrm{C}$ e extensão a $72^{\circ} \mathrm{C}$. Ao final do programa a temperatura se manteve a $72^{\circ} \mathrm{C}$ por cerca de 20 minutos.

Após a PCR, todas as amostras foram submetidas à técnica de eletroforese em gel de agarose 1,5X. Para tanto, usou-se $6 \mu \mathrm{L}$ da amostra amplificada e $2 \mu \mathrm{L}$ de tampão de corrida. Em cada poço do gel foi pipetado $5 \mu \mathrm{L}$ da mistura. A eletroforese ocorreu em cuba horizontal contendo TBE $1 \mathrm{X}$ e com os seguintes parâmetros: DDP de $100 \mathrm{~V}$ e corrente de 40 A por aproximadamente duas horas.

$A$ avaliação do padrão de inativação do cromossomo $X$ foi possível de ser alcançada a partir do estabelecimento da razão de inativação. Tal razão deve ser calculada ultilizando valores matemáticos dos picos de altura (amplificação) do menor alelo e a soma dos valores correspondentes aos dois alelos (Bittel, 2008). A correção do valor do pico de amplificação se deu usando-se a razão do valor do pico do alelo digerido e do mesmo alelo não digerido:

(phd1/phu1)/(phd1/phu1)+(phd2/phu2)

Onde:

- $\quad$ phd1 = alelo menor após digestão

- phu1 = alelo menor não digerido

- $\quad$ phd 2 = alelo maior após digestão

- $\quad$ phu $2=$ alelo maior não digerido 


\subsection{Eletroforese Capilar}

O material amplificado foi genotipado em sequenciador automático ABI-3130 (Life Technologies). Para tanto foi utilizado $1 \mu \mathrm{L}$ do material amplificado, $1 \mu \mathrm{L}$ de marcador de peso molecular GS500 LIZ (Applied Biosystems) e $9 \mu \mathrm{L}$ de formamida.

A análise dos dados gerados foi realizada utilizando-se o software Genemapper (Life Technologies). Todos os resultados das amostras nessa fase foram obtidos em parceria com o Laboratório de Ciências Genômicas e Biotecnologia Molecular da Universidade Católica de Brasília - Campus Asa Norte.

\subsection{Cariótipo}

A análise do cariótipo, com base na observação de 50 metáfases por individuos, coradas para bandeamento G, foi realizada pela Doutora Mara Santos Cordoba.

Para realização das lâminas para exame de cariótipo, foram coletados quatro mL de sangue periférico em tubo contendo heparina como agente anticoagulante. $\mathrm{Na}$ preparação da cultura temporária de linfócitos de sangue periférico, foi utilizado meio de cultura RPMI (Invitrogen, Carlsbad, EUA) suplementado com 15\% de soro bovino fetal (Invitrogen) e fitohematoglutinina (Gibco, BRL) na concentração final de $1 \%$.

A cultura foi incubada em estufa a $37^{\circ} \mathrm{C}$ por 72 horas e logo em seguida foi realizada a colheita das células para obtenção das preparações cromossômicas. Quarenta minutos antes da colheita, $50 \mu \mathrm{L}$ de colchicina (Sigma) a uma concentração de $4 \times 10^{-5}$ $\mathrm{M}$ foram acrescentados. A hipotonização foi feita em solução de $\mathrm{KCl}$ 0,075 M, por 10 minutos a $37^{\circ} \mathrm{C}$.

Para a fixação, foi utilizada uma solução álcool metílico e ácido acético na proporção 3:1. O produto a ser fixado foi pingado sobre lâminas conservadas em água destilada gelada e a secagem feita ao ar. As preparações cromossômicas foram mantidas à temperatura ambiente durante quatro a sete dias e então utilizadas para análise cromossômica. Foi utilizado microscópio óptico para analisar as amostras que foram previamente tratadas com tripsina e coloração com Giemsa (bandeamento G). 


\subsection{Análise Cromossômica por Microarranjos}

O exame de cariótipo utilizado para apontar alterações cromossômicas apresenta resolução de até 4-10Mb. Dessa maneira, para análise de alterações de menor tamanho se faz necessária a utilização de outras técnicas como maior poder de resolução.

A análise cromossômica por microarray faz parte do grupo de técnicas utilizadas na citogenética molecular para a triagem de alterações submicroscópicas. Com esta metodologia é possível detectar se há perdas ou ganhos de segmentos cromossômicos submicroscópicos do genoma do indivíduo. Assim, alterações cromossômicas de 10 a 100 vezes menores, que não seriam identificadas ao microscópio óptico, são registradas dependendo do filtro e da densidade dos marcadores.

Um conjunto de sondas (oligonucleotídeos) com localização previamente conhecida nos cromossomos é organizado em um Chip de DNA. A plataforma utilizada nesse estudo foi a CytoScan HD Array (Anffymetrix, EUA) e as imagens geradas pelo scanner GeneChip ${ }^{\circledR} 3000$ 7G System (Affymetrix, EUA) foram analisadas utilizando-se o programa ChAS versão 2.0.1.2.

Microarranjos de DNA contendo 2 milhões de sondas não polimórficas para Copy number variations (CNVs) de regiões codificantes e não codificantes e cerca de 750 SNPs são utilizados pela plataforma. O conjunto inclui os oligonucleotídeos do GeneChip®, reagentes, aparelho de hibridização, lavagem, coloração, leitura e visualização dos microarranjos, além do programa computacional responsável pela detecção dos Single nucleotide polymorphisms (SNPs) e das CNVs. A técnica apresentou as seguintes etapas:

Preparação do DNA genômico: de acordo com as recomendações do fabricante, para dar início à análise das amostras, estas deveriam apresentar uma concentração final de 50ng/ $\mu \mathrm{L}$ de DNA diluído em Low EDTA TE buffer (Affymetrix, EUA).

Digestão com Nsp I, ligação de adaptadores e amplificação: as amostras foram submetidas à digestão com uso da enzima Nsp I (Affymetrix, EUA) com a finalidade de obtenção de fragmentos de DNA de tamanhos variados e posterior ligação de adaptadores com a T4 DNA Ligase (Affymetrix, EUA). 
Preparação de uma mistura com $5 \mu \mathrm{L}$ de DNA, de $11,55 \mu \mathrm{L}$ de água (Chilled Affymetrix ${ }^{\circledR}$ Nuclease-Free Water), de 2,0 $\mu \mathrm{L}$ de tampão da Nsp I (10X), de 0,20 $\mu \mathrm{L}$ de albumina bovina sérica (BSA) (100X) e de $1,0 \mu \mathrm{L}$ da enzima Nsp I (10 U/ $\mu \mathrm{L})$. A seguir, a mistura foi colocada no termociclador MyCycler ${ }^{\circledR}$ (Bio-Rad, EUA) durante duas horas a $37^{\circ} \mathrm{C}$ e vinte minutos a $65^{\circ} \mathrm{C}$. Os produtos gerados pela digestão foram armazenados a $-20^{\circ} \mathrm{C}$.

A ligação dos fragmentos de DNA aos adaptadores específicos foi realizada a partir da mistura de $0,75 \mu \mathrm{L}$ de adaptador Nsp I $(50 \mu \mathrm{M}), 2,50 \mu \mathrm{L}$ de tampão da T4 DNA Ligase $(10 \mathrm{X})$ e $2,00 \mu \mathrm{L}$ da enzima T4 DNA Ligase $(400 \mathrm{U} / \mu \mathrm{L})$. A mistura foi colocada no aparelho termociclador (Bio-Rad, EUA) durante três horas a $16^{\circ} \mathrm{C}$ e 20 minutos a $70^{\circ} \mathrm{C}$. Os produtos dessa reação foram diluídos com $75 \mu \mathrm{L}$ de água e armazenados a $20^{\circ} \mathrm{C}$.

Quadruplicatas das reações de PCR foram feitas para aumentar a quantidade do DNA genômico. Os fragmentos de DNA ligados a adaptadores Nsp I foram submetidos à reação de PCR com a utilização de $39,5 \mu \mathrm{L}$ de água, $10,0 \mu \mathrm{L}$ de tampão da TITANIUMTMTaq DNA Polimerase (10X), 20 $\mu \mathrm{L}$ de reagente GC-Melt, $14,0 \mu \mathrm{L}$ de mistura de dNTP's (2,5mM cada), 4,5 $\mathrm{L}$ do iniciador PCR Primer $002(100 \mu \mathrm{M})$ (Clontech, EUA) e 2,0 $\mu \mathrm{L}$ da enzima TITANIUM ${ }^{\mathrm{TM}}$ Taq DNA polimerase (50X) (Clontech, EUA). As amostras foram colocadas no aparelho termociclador Veriti ${ }^{\mathrm{TM}}$ onde as reações tinham 1 ciclo de incubação a $94^{\circ} \mathrm{C}$ ( 3 minutos), 30 ciclos de $94^{\circ} \mathrm{C}(30$ segundos), $60^{\circ} \mathrm{C}$ (45 segundos) e $68^{\circ} \mathrm{C}$ (15 segundos) e um último ciclo de $68^{\circ} \mathrm{C}$ (sete minutos).

Foi preparado um gel de agarose a $2 \%$ corado com brometo de etídio para visualização dos produtos da PCR, sendo que o sucesso da ligação, digestão e PCR foi confirmado pela visualização de fragmentos de 150 a 2000pb. Resultado positivo nessa fase é crucial para sequências posteriores do protocolo.

Mistura dos produtos das PCRs, purificação e quantificação: Os produtos das PCRs das quadruplicatas de cada amostra foram colocados em um único tubo (volume final $397 \mu \mathrm{L}$ ), sendo os fragmentos de DNA capturados com o auxílio de esferas magnéticas (Affymetrix, EUA). Após incubação e centrifugação, as esferas magnéticas contendo os fragmentos de DNA aderidos a sua superfície foram selecionadas por força magnética na MagnaRacK ${ }^{\mathrm{TM}}$ (Life Technologies, EUA), lavadas com tampão de 
purificação (Affymetrix, EUA) e, finalmente , os DNAs eluídos em tampão de eluição (Affymetrix, EUA) para um volume final de $47 \mu \mathrm{L}$. O material foi quantificado no espectrofotômetro Nano Vue Plus, a concentração de DNA esperada para esta fase é de $>3.0 \mu \mathrm{g} / \mu \mathrm{L}$.

Fragmentação dos produtos das PCRs: foi preparada uma mistura dos produtos das PCRs com $10 \mu \mathrm{L}$ do mix de fragmentação que consiste em:123,5 $\mu \mathrm{L}$ de água, $158,4 \mu \mathrm{L}$ de tampão de fragmentação $10 \mathrm{X}$ (Affymetrix, EUA) e $5,8 \mu \mathrm{L}$ do reagente de fragmentação $(2,5 \mathrm{U} / \mu \mathrm{L})$. Essa mistura foi colocada no termociclador VeritiTM por trinta e cinco minutos a $37^{\circ} \mathrm{C}$ e quinze minutos a $95^{\circ} \mathrm{C}$. A presença de fragmentos entre $25 \mathrm{e}$ $125 \mathrm{pb}$ pela eletroforese em gel de agarose $4 \%$ corado com brometo de etídio confirma a fragmentação.

Marcação do DNA fragmentado com biotina: uma mistura foi preparada entre $51 \mu \mathrm{L}$ do DNA fragmentado e $19,5 \mu \mathrm{L}$ da mistura de marcação $(14,0 \mu \mathrm{L}$ de tampão Terminal deoxynucleotidyl Transferase (5X), 2,0 $\mu \mathrm{L}$ de reagente de marcação de DNA $30 \mathrm{mM}$ (biotina) e $3,5 \mu \mathrm{L}$ da enzima TdT (30 U/ $\mu \mathrm{L})$. Essa mistura foi colocada em um termociclador Veriti ${ }^{\mathrm{TM}}$ durante quatro horas a $37^{\circ} \mathrm{C}$ e 15 minutos a $95^{\circ} \mathrm{C}$.

Hibridização: a mistura de hibridização foi previamente preparada com tampão de hibridização parte $1(165,0 \mu \mathrm{L})$, parte $2(15,0 \mu \mathrm{L})$, parte $3(7,0 \mu \mathrm{L})$ e parte $4(1,0 \mu \mathrm{L})$, mais $2,0 \mu \mathrm{L}$ de OCR (Oligo Control Reagent, Affymetrix, EUA). Em seguida, 70,5 $\mu \mathrm{L}$ de DNA biotililado e $190 \mu \mathrm{L}$ da mistura de hibridização foram reunidos. Esta mistura foi aquecida no termociclador Veriti ${ }^{\mathrm{TM}}$ a $95^{\circ} \mathrm{C}$ por dez minutos e resfriada a $49^{\circ} \mathrm{C}$ até a etapa seguinte. Mantendo-se a amostra no termociclador, $200 \mu \mathrm{L}$ da mistura desnaturada foi depositada imediatamente em cada um dos GeneChip ${ }^{\circledR}$ com os oligonuclotídeos pré-arranjados. A incubação dos GeneChip ${ }^{\circledR}$ ocorreu no forno de hibridização (modelo Hybridization Oven 645, Affymetrix, EUA) a $50^{\circ} \mathrm{C}$ durante 16 a 18 horas a $60 \mathrm{rpm}$.

Lavagens dos GeneChip® e marcação com fluoróforos: realizada na estação automatizada Fluidics Station 450 (Affymetrix, EUA). Os GeneChip® foram retirados do forno de hibridização e colocados na estação fluídica onde as lavagens e marcações por fluoróforos dos microarranjos contidos nos chips são automatizados sob controle do software Affymetrix GeneChip®. 
Varredura dos GeneChip®, captação de imagens e análise no software Chromosome Analysis Suite 1.2.2 (Affymetrix ${ }^{\circledR}$ ): os chips foram colocados no GeneChip ${ }^{\circledR}$ Scanner 3000 7G. As imagens geradas pela excitação dos fluoróforos foram captadas pelo digitalizador e passaram pelo controle de qualidade através do programa Genotyping Console versão 3.2.2 (Affymetrix, EUA), e pelo programa de visualização Affymetrix GeneChip Viewer as imagens dessas leitura puderam ser observadas.

Por fim, ao utilizar o software Chromosome Analysis Suite (ChAS) versão 1.2.2 (Affymetrix, EUA) foi possível visualizar e analisar as alterações cromossômicas (duplicações, deleções, CNVs, mosaicismo, perda de heterozigose) ao longo do genoma de cada amostra. O programa é oferecido gratuitamente no sítio do fabricante (www.affymetrix.com) e trabalha com a interface do Windows 7. 


\section{RESULTADOS E DISCUSSÃO}

A investigação do padrão de inativação do cromossomo $\mathrm{X}$ pode ser utilizada para identificar possíveis associações entre o desvio total de inativação do cromossomo $\mathrm{X}$ e mutações nesse cromossomo. Desvios têm sido relatados como estando relacionados a mutações no cromossomo $\mathrm{X}$, sejam mutações estruturais com CNVs, como mutações de ponto, por exemplo. Tendo em vista a associação entre desvio de inativação do X e deficiência intelectual, buscou-se nesse estudo a análise desse fenômeno biológico em uma amostra de população brasileira que não apresentava histórico familiar de deficiência intelectual.

Foram pesquisados os padrões de inativação do cromossomo X em 102 mulheres com idade igual ou maior que 35 anos, sem histórico familiar para deficiência intelectual ligada ao $\mathrm{X}$ e/ou autismo, e com ao menos um filho biológico do sexo masculino. As mulheres convidadas a participarem do estudo residiam em Brasília ou na região do Entorno do Distrito Federal.

\subsection{Caracterização da Amostra}

A amostra foi constituída de mulheres de diferentes classes sociais, diferentes graus de instrução, excluindo-se as analfabetas, e atividades profissionais diversificadas, como donas de casa, profissionais autônomas, servidoras públicas, dentre outras.

A autoclassificação fenotípica revelada pelos questionários (Anexo 1) apontou que a amostra pesquisada encontrou-se dividida em três grandes grupos: "branco", "negro" e "misto" (Figura 4). Das 102 mulheres, todas responderam ao critério de autoclassificação fenotípica, desse total, 55 se declararam pertencentes ao grupo "misto", 31 ao "branco", 15 ao "negro" e uma se declarou pertencente ao grupo "ameríndio". 


\section{Autoclassificação fenotípica}

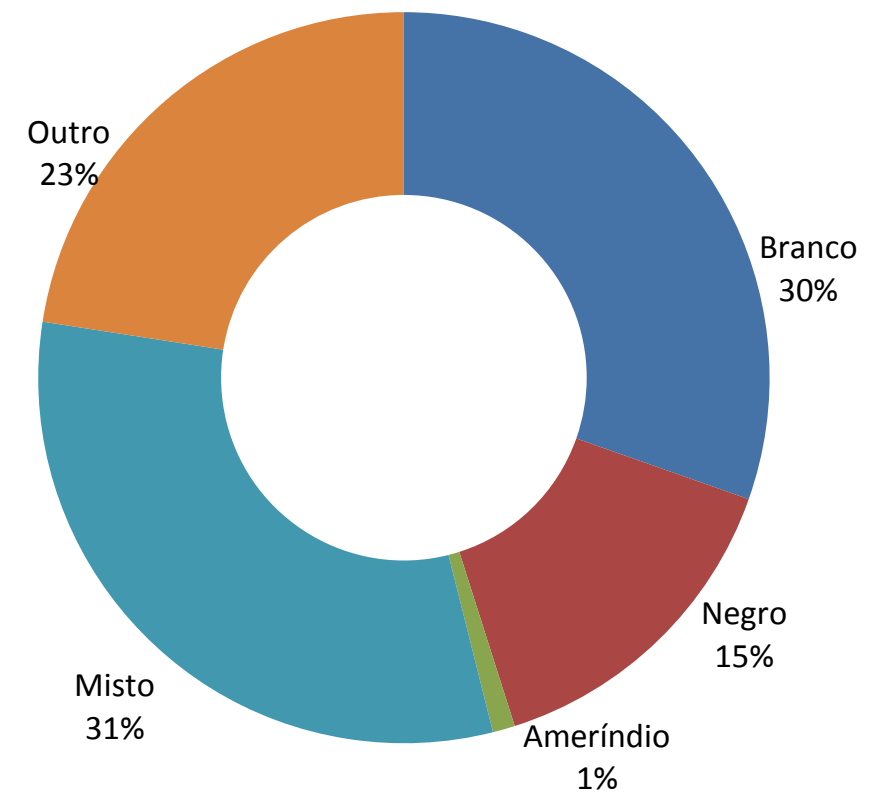

Figura 4. Distribuição, em porcentagem, da autoclassificação fenotípica das mulheres participantes.

Foi observada a predominância de mulheres que se declararam dos grupos "branco" e "misto", assim como ocorre com a população geral do Distrito Federal (IBGE, 2013). A Tabela 1 apresenta uma comparação entre a autoclassificação das mulheres da amostra aqui utilizada e a população do Distrito Federal de acordo com o IBGE.

Tabela 1. Comparação da autoclassificação fenotípica entre a amostra pesquisada e os dados do IBGE.

\begin{tabular}{lrrrrr}
\hline & Branco & Negro & Ameríndio & Misto & Total \\
\hline Amostra & 31 & 15 & 1 & 55 & 102 \\
Brasília & 30 & 11 & 1 & 53 & 100 \\
\hline
\end{tabular}

As mulheres participantes da pesquisa apresentavam naturalidade de diversas regiões do Brasil, fato este que revela o caráter heterogêneo para a constituição da 
amostra. Brasília tornou-se a capital do país em 1960, sendo que naquela época houve uma grande oferta de postos de trabalho que, prioritariamente, visava à construção da cidade. A nova capital atraiu famílias de várias regiões do país e tornou-se, desde aquela época, uma das cidades brasileiras que mais recebe migrantes. A região Nordeste foi a que mais contribuiu para a manutenção do fluxo migratório com foco em Brasília, seguida pelo estado de Minas Gerais e Goiás, respectivamente (Carvalho, 2008). A amostra indicou que das 102 mulheres participantes, 40 eram provenientes da região Nordeste, 34 da região Centro-Oeste (incluindo Brasília), 19 do Sudeste, sete do Norte e duas da região Sul (Figura 5). Essa forma de distribuição coincide com a encontrada pelo IBGE acerca de estudos sobre autoclassificação, e reforça a predominância de indivíduos nascidos na região Nordeste para constituição da amostra de população residente em Brasília, ainda, foi possível notar que é crescente a contribuição quatitativa de indivíduos nascidos na região Centro-Oeste, especificamente em Brasília, e que continuam a viver nessa cidade.

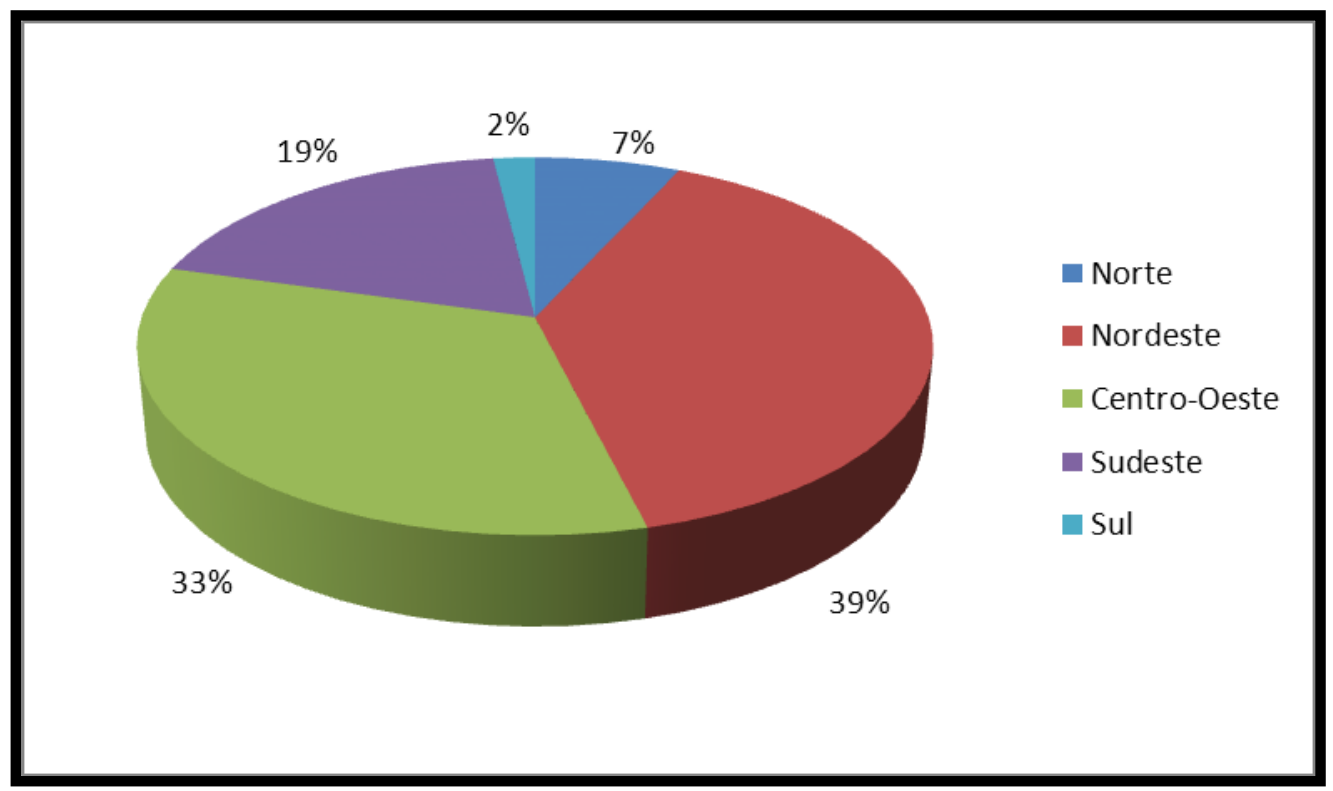

Figura 5. Distribuição, em porcentagem, dos locais de nascimento das mulheres participantes da amostra.

A idade das mulheres variou entre 35 anos (idade mínima de participação na pesquisa) e 66 anos, apresentando média de 46,2 e moda 41. A população feminina no Distrito Federal pertencente à média de idade apresentada pela amostra foi estimada em 84.568 mulheres em 2010 (IBGE, 2010). Outra característica da amostra revelou idade 
média de menarca das mulheres de 13,3, moda 14, valor próximo da média nacional. A taxa de fecundidade que correspondeu ao número de gestações confirmadas para cada mulher apresentou o valor médio de 2,9 e moda 2 . Dentre as mulheres que compuseram a amostra, 46\% apresentaram histórico familiar de câncer (Tabela 2).

\subsection{Perfil de Inativação do cromossomo $X$}

As amostras das 102 mulheres participantes desse estudo foram analisadas quanto ao padrão de inativação do cromossomo $X$ a partir da avaliação de metilação do gene AR (Androgen Receptor). Mediante a análise do eletroferograma, foi possível estimar a porcentagem de cromossomos paternos e maternos inativados em cada amostra. As Figuras 6.A e 6.B mostram dois eletroferograma nos quais os picos registrados revelam o genótipo para a reação da amostra não digerida e digerida, respectivamente. Pode-se observar pela comparação entre os dois eletroferogramas que esse indivíduo apresentou desvio total de inativação do cromossomo X. Essa conclusão baseia-se no fato que o eletroferograma da amostra com digestão apresentou apenas um pico enquanto que a não digerida apresentou dois, revelando que a mulher é heterozigota para o gene $A R$, mas que um dos cromossomos foi preferencialmente inativado. Todas as mulheres que participaram da pesquisa se revelaram heterozigóticas para a repetição polimórfica $\mathrm{CAG}$ presente no sítio de restrição do gene $A R$.

As Figuras 7 e 8 demonstram, respectivamente, os resultados encontrados em amostra sem desvio total de inativação e amostra controle masculino normal. O padrão de inativação do cromossomo $X$ em que o mesmo cromossomo X está inativo em $43 \%$ das células do sangue periférico (razão de inativação 43:57) está demonstrado na Figura 7. Esse é exemplo de resultado esperado para o padrão normal de inativação do cromossomo $X$, ou seja, a razão entre os cromossomos não ultrapassa a razão ( $\geq 95: 5)$ ou ( $\geq 5: 95)$. A Figura 8 apresenta as reações sem digestão e com digestão da amostra controle masculina, respectivamente. Como o único cromossomo $\mathrm{X}$ encontra-se ativo em todas as células do sangue periférico, espera-se que a enzima HhaI atue sobre o DNA da amostra e, consequentemente, impeça que a reação de amplificação aconteça, o que resulta na ausência de picos de amplificação para o produto dessa digestão. 
A

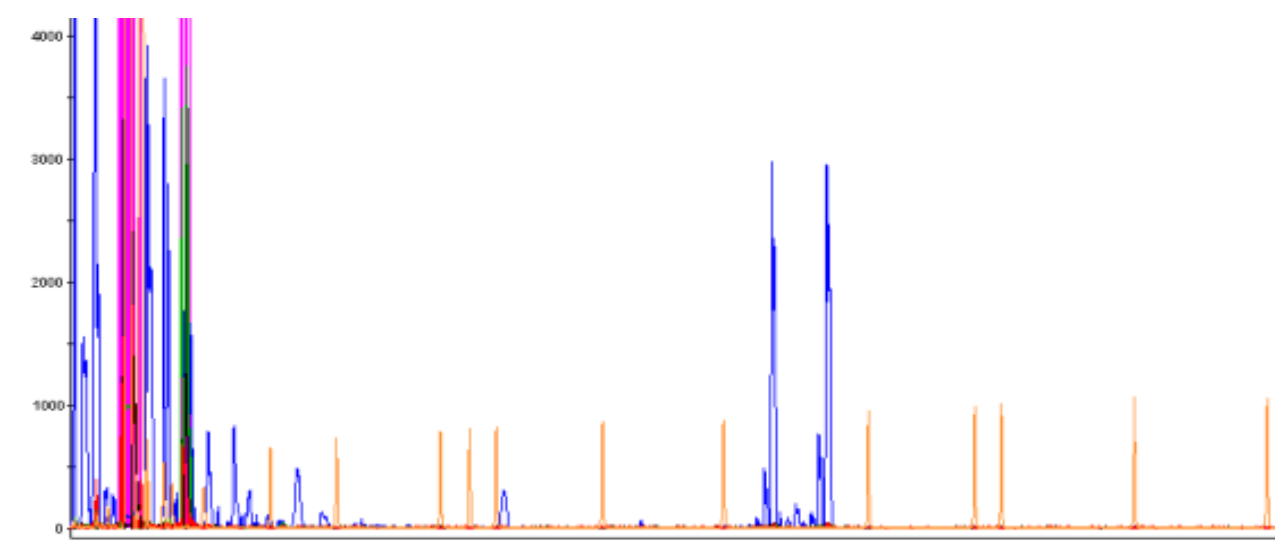

B

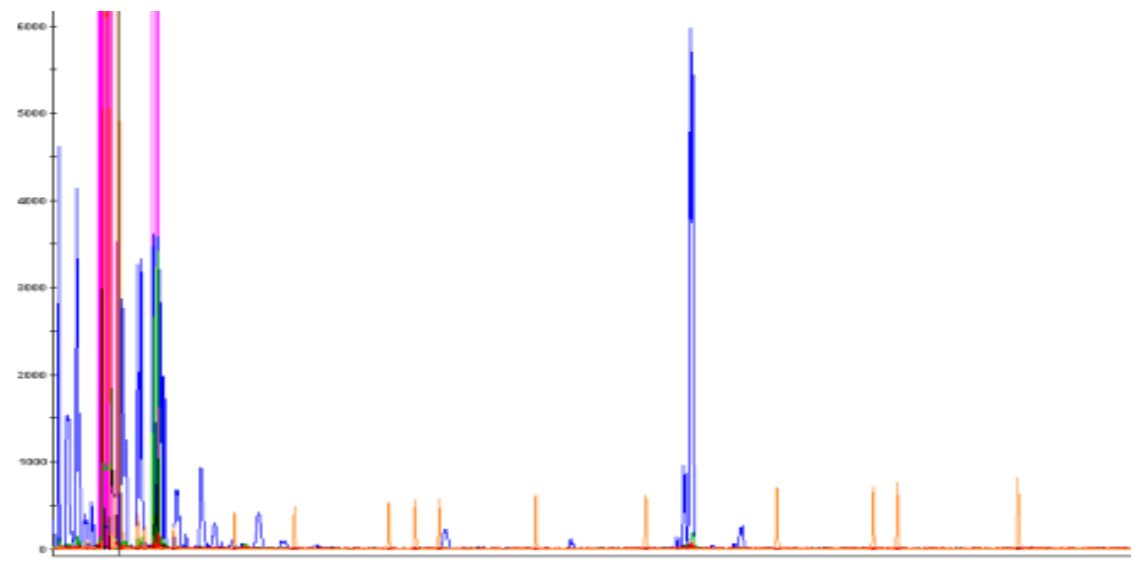

Figura 6. A. Picos de amplificação dos dois alelos antes do tratamento com enzima Hha I; B. Pico de amplificação de apenas um alelo após o tratamento enzimático. Resultado de desvio total de inativação do cromossomo $\mathrm{X}$, ou seja, existe preferencialmente a inativação de um dos cromossomo X. 
A

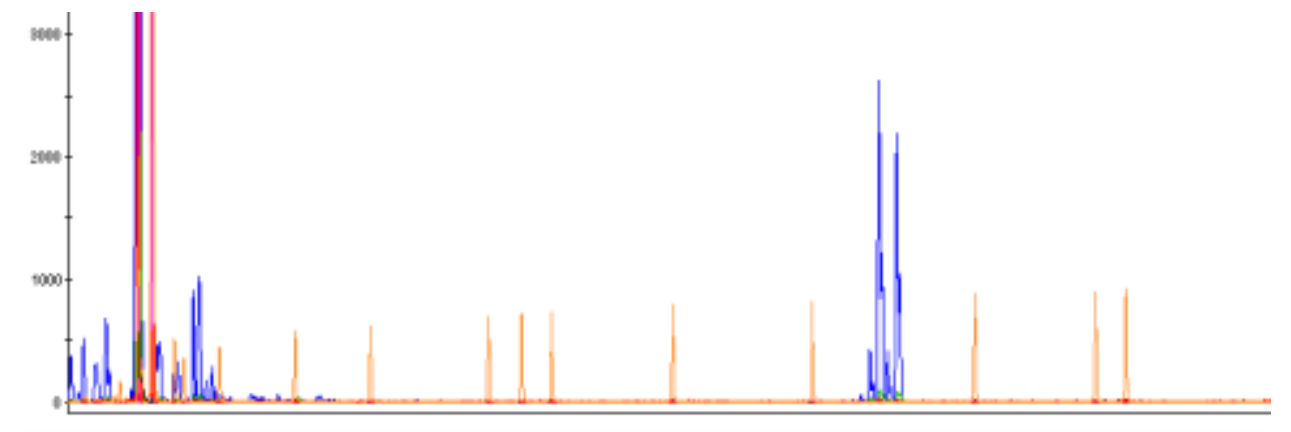

B

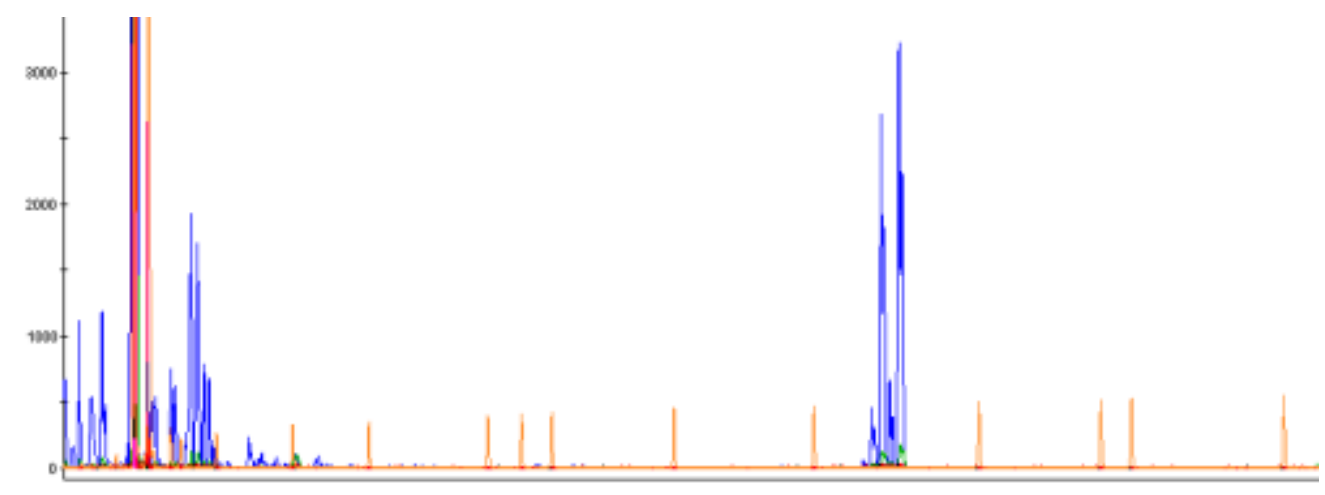

Figura 7. A. Resultado da amplificação da amostra sem o tratamento enzimático; B. Resultado da amplificação da amostra após o tratamento enzimático. Percebe-se que há semelhança entre os picos das duas reações. 


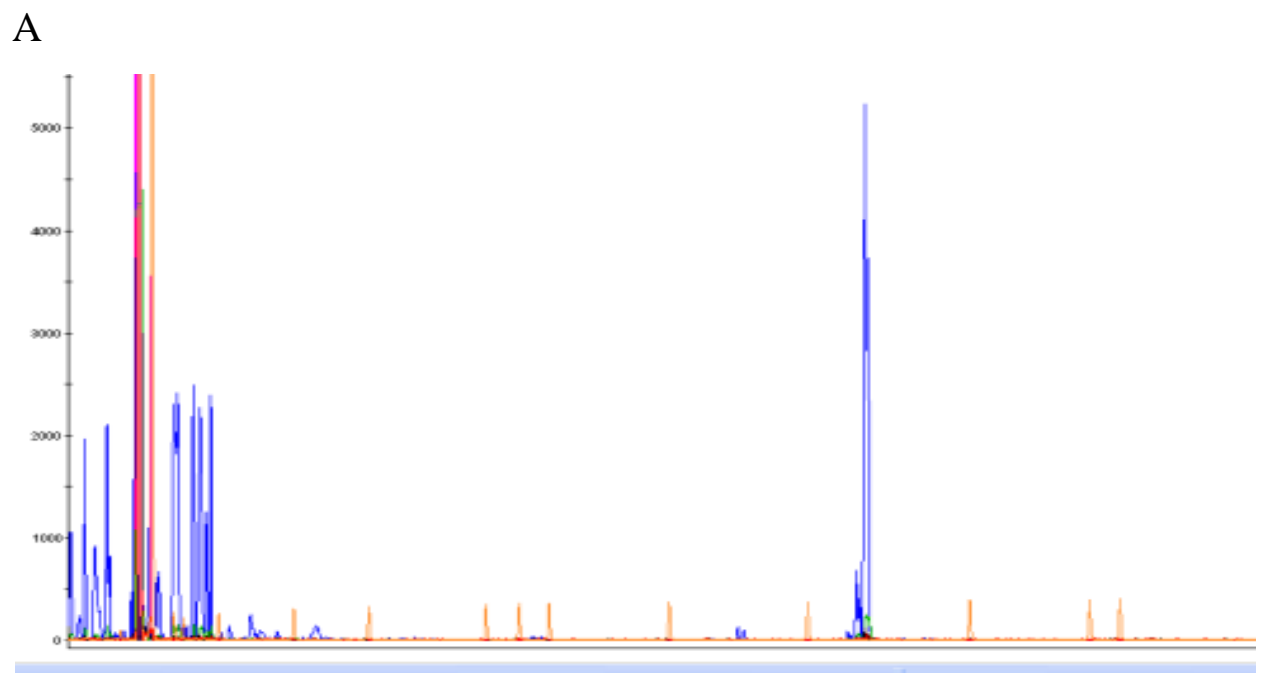

B

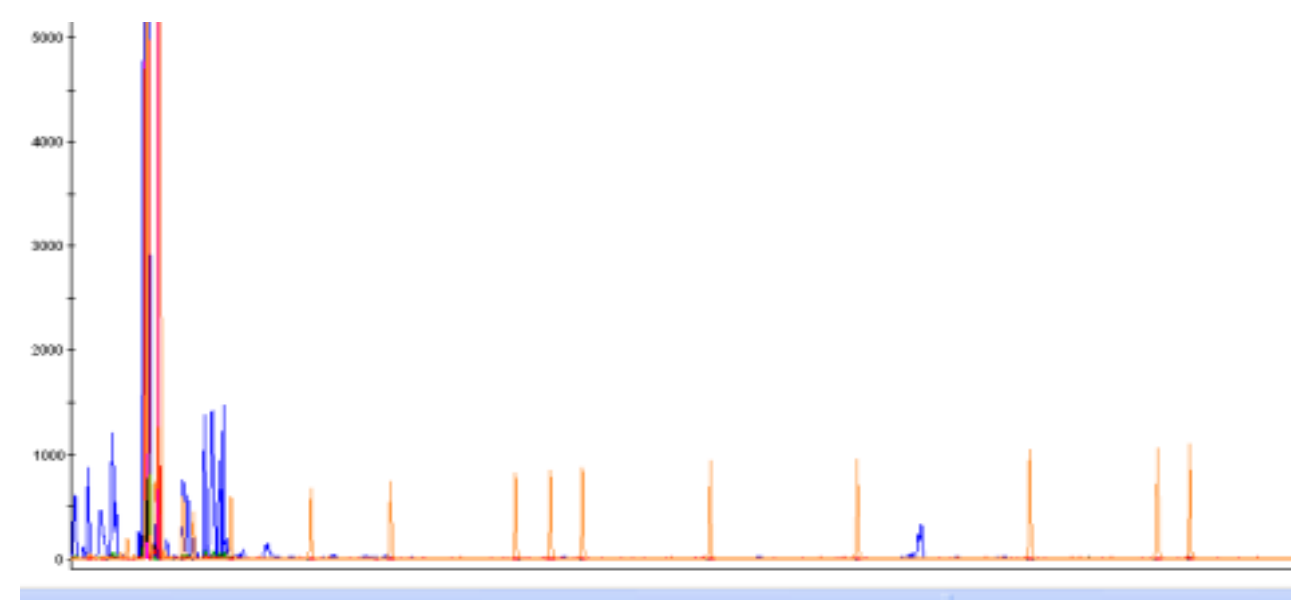

Figura 8. A. Amostra controle, masculina, sem tratamento enzimático; B. Amostra controle, masculina, após tratamento enzimático. Percebe-se que não houve amplificação significativa da amostra, uma vez que o único cromossomo X no homem encontra-se ativo e deverá ser digerido. 
Tabela 2. Resultado do Padrão de Inativação do Cromossomo X (Razão de inativação do $\mathrm{X}$ ), idade, idade de menarca e relato de câncer na família em amostra de população brasileira sem histórico familiar para deficiência intelectual e ou autismo.

\begin{tabular}{|c|c|c|c|c|}
\hline Amostra & $\begin{array}{c}\text { Razão de } \\
\text { inativação do X }\end{array}$ & $\begin{array}{l}\text { Idade } \\
\text { (anos) }\end{array}$ & $\begin{array}{c}\text { Idade Menarca } \\
\text { (anos) }\end{array}$ & Câncer na família \\
\hline X 01 & $(31: 69)$ & 39 & 12 & -- \\
\hline X 02 & $(46: 54)$ & 46 & 13 & --- \\
\hline X 03 & $(47: 53)$ & 55 & 11 & Útero/Ovário \\
\hline X 04 & $(26: 74)$ & 38 & 12 & --- \\
\hline X 05 & $(47: 53)$ & 51 & 12 & --- \\
\hline X 06 & $(18: 82)$ & 60 & 16 & Pele \\
\hline X 07 & $(52: 48)$ & 39 & 13 & --- \\
\hline X 08 & $(84: 16)$ & 35 & 15 & Ovário/Intestino \\
\hline X 09 & $(87: 13)$ & 42 & 14 & --- \\
\hline X 10 & $(37: 63)$ & 45 & 12 & --- \\
\hline X 11 & $(32: 68)$ & 51 & 13 & Pulmão/Ovário \\
\hline $\mathbf{X} 12$ & $(50: 50)$ & 41 & 14 & Mama/Pulmão \\
\hline X 13 & $(61: 39)$ & 37 & 14 & --- \\
\hline X 14 & $(56: 44)$ & 38 & 12 & --- \\
\hline X 15 & $(29: 71)$ & 55 & 14 & --- \\
\hline X 16 & $(66: 34)$ & 37 & 15 & Estômago \\
\hline X 17 & $(53: 47)$ & 54 & 14 & --- \\
\hline $\mathrm{X} 18$ & $(15: 85)$ & 46 & 13 & --- \\
\hline X 19 & $(86: 14)$ & 55 & 13 & --- \\
\hline $\mathbf{X} 20$ & $(18: 82)$ & 52 & 13 & Boca \\
\hline $\mathbf{X} 21$ & $(46: 54)$ & 45 & 13 & Intestino \\
\hline X 22 & $(15: 85)$ & 54 & 14 & Mama \\
\hline X 23 & $(47: 53)$ & 57 & 13 & Mama \\
\hline X 24 & $(20: 80)$ & 54 & 11 & --- \\
\hline $\mathbf{X} 25$ & $(88: 12)$ & 40 & 12 & Pulmão \\
\hline X 26 & $(44: 56)$ & 49 & 15 & Útero \\
\hline X 27 & $(06: 94)$ & 57 & 14 & Intestino \\
\hline X 28 & $(34: 66)$ & 51 & 13 & Próstata/Cérebro \\
\hline $\mathbf{X 2 9}$ & $(68: 32)$ & 37 & 9 & Esôfago/Intestino \\
\hline
\end{tabular}




\begin{tabular}{|c|c|c|c|c|}
\hline X 30 & $(62: 38)$ & 53 & 14 & --- \\
\hline X 31 & $(33: 67)$ & 45 & 12 & --- \\
\hline X 32 & $(49: 51)$ & 36 & 11 & --- \\
\hline X 33 & $(32: 68)$ & 50 & 13 & --- \\
\hline X 34 & $(35: 65)$ & 56 & 14 & --- \\
\hline X 35 & $(77: 23)$ & 46 & 15 & --- \\
\hline X 36 & $(48: 52)$ & 46 & 13 & --- \\
\hline X 37 & (60:40) & 55 & 13 & --- \\
\hline X 38 & $(25: 75)$ & 50 & 12 & --- \\
\hline X 39 & (94:06) & 50 & 10 & --- \\
\hline X 40 & (93:07) & 48 & 11 & Mama \\
\hline X 41 & $\begin{array}{l}(20: 80) \\
\end{array}$ & 54 & 16 & ---- \\
\hline $\mathrm{X} \mathrm{42}$ & $(70: 30)$ & 38 & 13 & --- \\
\hline$\times 43$ & $(36: 64)$ & 54 & 9 & --- \\
\hline $\mathrm{X} \mathrm{44}$ & $(46: 54)$ & 59 & 12 & --- \\
\hline X 45 & $(09: 91)$ & 52 & 12 & --- \\
\hline X 46 & $(49: 51)$ & 41 & 13 & --- \\
\hline X 47 & $(80: 20)$ & 51 & 14 & Reto \\
\hline X 48 & $(24: 76)$ & 43 & 11 & --- \\
\hline X 49 & $(42: 58)$ & 41 & 13 & --- \\
\hline X 50 & $(64: 36)$ & 37 & 15 & --- \\
\hline X 51 & $(61: 39)$ & 46 & 14 & Reto \\
\hline X 52 & $(56: 44)$ & 65 & 15 & Mama \\
\hline X 53 & (96:04) & 39 & 15 & Orelha \\
\hline X 54 & $(48: 52)$ & 48 & 14 & --- \\
\hline X 55 & $(37: 63)$ & 39 & 12 & --- \\
\hline X 56 & $(57: 43)$ & 47 & 12 & --- \\
\hline X 57 & $(42: 58)$ & 47 & 12 & Tireóide \\
\hline X 58 & (46:54) & 38 & 11 & --- \\
\hline X 59 & $(33: 67)$ & 53 & 12 & Fígado \\
\hline X 60 & $(02: 98)$ & 66 & 17 & Intestino \\
\hline X 61 & $(46: 54)$ & 49 & 15 & Estômago \\
\hline $\mathrm{X} \mathrm{62}$ & $(36: 64)$ & 46 & 14 & --- \\
\hline X 63 & $(47: 53)$ & 50 & 12 & Estômago \\
\hline X 64 & $(54: 46)$ & 55 & 13 & --- \\
\hline $\mathbf{X 6 5}$ & $(15: 85)$ & 44 & 17 & Rim \\
\hline X 66 & $(43: 57)$ & 39 & 14 & --- \\
\hline X 67 & $(27: 73)$ & 49 & 16 & --- \\
\hline X 68 & $(72: 28)$ & 41 & 14 & --- \\
\hline
\end{tabular}




\begin{tabular}{|c|c|c|c|c|}
\hline X 69 & $(32: 68)$ & 40 & 15 & --- \\
\hline X 70 & $(27: 73)$ & 42 & 13 & --- \\
\hline X 71 & $(87: 13)$ & 44 & 14 & Próstata \\
\hline X 72 & $(22: 78)$ & 51 & 14 & Pulmão \\
\hline X 73 & $(62: 38)$ & 41 & 16 & Mama \\
\hline$\times 74$ & $(21: 79)$ & 51 & 11 & --- \\
\hline X 75 & $(29: 71)$ & 40 & 14 & Pâncreas \\
\hline X 76 & $\begin{array}{l}(24: 76) \\
\end{array}$ & 39 & 15 & Próstata/Garganta \\
\hline X 77 & $(29: 71)$ & 57 & 15 & Pulmão \\
\hline X 78 & $(40: 60)$ & 44 & 15 & --- \\
\hline X 79 & $(33: 67)$ & 43 & 12 & --- \\
\hline $\mathbf{X ~ 8 0}$ & (34:66) & 35 & 13 & --- \\
\hline X 81 & $(43: 57)$ & 47 & 12 & Mama/Fígado \\
\hline X 82 & $(62: 38)$ & 37 & 13 & Mama/Estômago \\
\hline $\mathbf{X ~ 8 3}$ & $(81: 19)$ & 40 & 11 & $\begin{array}{l}-- \\
\end{array}$ \\
\hline X 84 & $(96: 04)$ & 43 & 16 & Esôfago \\
\hline X 85 & $(17: 83)$ & 43 & 12 & Rim/Pulmão \\
\hline X 86 & $(39: 61)$ & 36 & 13 & --- \\
\hline $\mathbf{X ~} 87$ & $(24: 76)$ & 44 & 11 & Útero \\
\hline $\mathbf{X ~} 88$ & $(52: 48)$ & 37 & 15 & Mama \\
\hline$\times 89$ & $(36: 64)$ & 40 & 14 & Pele \\
\hline $\mathbf{X ~ 9 0}$ & $(46: 54)$ & 41 & 18 & Cérebro \\
\hline X 91 & $(73: 27)$ & 52 & 14 & Mama \\
\hline X 92 & $(57: 43)$ & 46 & 13 & Tireóide \\
\hline X 93 & $(17: 83)$ & 40 & 12 & Boca \\
\hline X 94 & $(51: 49)$ & 40 & 14 & --- \\
\hline $\mathbf{X} 95$ & $(51: 49)$ & 40 & 14 & --- \\
\hline X 96 & $(32: 68)$ & 49 & 10 & Próstata \\
\hline X 97 & $(15: 85)$ & 51 & 12 & Esôfago \\
\hline X 98 & $(67: 33)$ & 41 & 13 & Estômago \\
\hline X 99 & $(03: 97)$ & 37 & 14 & --- \\
\hline $\mathbf{X} 100$ & $(36: 64)$ & 41 & 17 & $\begin{array}{l}-- \\
\end{array}$ \\
\hline X 101 & $(80: 20)$ & 50 & 12 & Mama \\
\hline X 102 & $(39: 61)$ & 57 & 13 & --- \\
\hline
\end{tabular}


A análise dos perfis de inativação das 102 mulheres participantes da pesquisa indicou que quatro delas apresentaram o desvio total de inativação do cromossomo $\mathrm{X}$ (Tabela 3). Ou seja, 3\% da amostra apresentou uma razão de inativação entre os dois cromossomos $X \geq 95: 5$ ou $\geq 5: 95$. O trabalho mais relevante de estudo de desvio de inativação em mulheres não afetadas da população geral relatou $8 \%$ das amostras com desvio, porém considerando o valor de corte de $\geq 80: 20$ ou $\geq 20: 80$ (Amos-Landgraf, 2006). Se considerarmos esse valor de corte, o número de amostras do presente estudo que apresentou desvio de inativação seria 26, isso é, 25,5\% da amostra (Tabela 3), valor esse muito acima do encontrado anteriormente. Essa diferença pode ser decorrente do perfil genético da amostra analisada. A população brasileira é uma população essencialmente miscigenada, enquanto que a amostra analisada por Amos-Landgraf, (2006), apesar dos autores colocarem que é uma amostra mista, foi composta por uma variedade de povos, o que incluiu grupos fechados como o grupo Mennonite da Pensilvânia e mulheres de etnia judia Askenazi.

Tabela 3. Resultado dos padrões de inativação do cromossomo X das mulheres estudadas.

\begin{tabular}{lrr}
\hline Padrão de Inativação do Cromossomo X & Total & \% \\
\hline Com desvio $\geq 95: 5$ ou $\geq 5: 95$ & 4 & 3,0 \\
Com desvio $\geq 80: 20$ ou $\geq 20: 80$ & 26 & 25,5 \\
\hline
\end{tabular}

Dentre as quatro mulheres que apresentaram resultado positivo para o padrão de inativação com desvio total, três delas responderam na entrevista que tinham casos de câncer na família, dentre os tipos: esôfago, intestino e orelha. A faixa etária dessas quatro mulheres apresentou média de 46 anos, nenhuma delas relatou aborto espontâneo, a média de quantidade de partos foi de 2,5, tendo todas pelo menos um menino e uma menina (Tabela 4). Das 26 mulheres com desvio $\geq 80: 20$ ou $\geq 20: 80,17$ delas, isso é, 65\%, apresentam histórico de câncer na família, número esse bem acima do observado na amostra como um todo, $46 \%$, sugerindo mais uma vez que a associação observada entre câncer e desvio de inativação não deva ser uma associação espúria. 
Estudos descrevem a presença de desvio de inativação do cromossomo $\mathrm{X}$ em células cancerosas (Chaligné \& Heard, 2014), o que revela a importância de se estudar esse fenômeno biológico. Foi descrito, por exemplo, a ocorrência de desvio de inativação do cromossomo $\mathrm{X}$ em células de câncer de mama. $\mathrm{O}$ gene BRCAI, de acordo com estudos, tem uma ação direta no produto do gene XIST, o que influencia diretamente a inativação do cromossomo X (Ganesan, 2002). Outras correlações foram também descritas entre genes relacionados a câncer e desvio de inativação do cromossomo X (Chaligné \& Heard, 2014). Essa correlação entre resultado positivo para o desvio total de inativação do cromossomo $\mathrm{X}$ e histórico familiar de diferentes casos de câncer aponta que esses dois eventos poderiam estar relacionados.

Tabela 4. Dados coletados em entrevista para as quatro mulheres que apresentaram desvio total de inativação do cromossomo X

\begin{tabular}{lcllccc}
\hline Amostra & $\begin{array}{c}\text { Idade } \\
\text { (anos) }\end{array}$ & Natural de & Residente em & $\begin{array}{c}\text { Histórico } \\
\text { familiar } \\
\text { para } \\
\text { câncer }\end{array}$ & $\begin{array}{c}\text { Relato de } \\
\text { Aborto }\end{array}$ & $\begin{array}{c}\text { Número } \\
\text { de partos }\end{array}$ \\
\hline X53 & 39 & Brasília & Lago Azul/GO & Positivo & - & 2 \\
X60 & 66 & Maranhão & Samambaia/DF & Positivo & - & 4 \\
& & & São & & & \\
X84 & 43 & Bahia & Sebastião/DF & Positivo & - & 3 \\
X99 & 37 & Maranhão & Paranoá/DF & Negativo & - & 2 \\
\hline
\end{tabular}

\subsection{Cariótipo}

As quatro voluntárias que apresentaram desvio total de inativação do cromossomo $\mathrm{X}$ tiveram suas amostras submetidas ao exame de cariótipo. Foram analisadas cinquenta (50) metáfases coradas para bandeamento G, obtidas a partir de cultura temporária de linfócitos do sangue periférico. Todas as quatro amostras apresentavam cromossomos normais, em número e em estrutura. A literatura traz uma série de exemplos sobre 
inativação do cromossomo $\mathrm{X}$ utilizando o cariótipo para identificação de aberrações cromossômicas presentes no cromosmo X, como por exemplo, em mulheres portadoras da síndrome de Turner, que apresentam um quadro clínico com má-formação uterina, baixa estatura, entre outros achados. Contudo, em mulheres portadoras dessa síndrome pode haver inativação preferencial do cromossomo portador de mutação, na tentativa de preservar aqueles que contribuem para sua composição gênica equilibrada (Leppig, 2004; Leppig \& Disteche, 2001). No caso das amostras aqui analisadas com desvio de inativação, a ocorrência de alterações cromossomicas visíveis em microscopia óptica foi descartada.

\subsection{Análise Cromossômica por Microarranjos}

As quatro mulheres que apresentaram desvio total de inativação do cromossomo $\mathrm{X}$ tiveram suas amostras analisadas quanto a alterações cromossomicas submicroscópicas cromossômica pelo microarray Cytoscan HD (Affymetrix). Como resultado, não foram observados microarranjos patogênicos para o cromossomo $\mathrm{X}$ ou outro cromossomo com o uso dessa técnica. O resultado da análise cromossômica por microarranjos para as quatro mulheres que apresentaram o padrão desviado de inativação do cromossomo $X$ está representados nas Figuras 9, 10, 11, 12 e 13. A amostra X53 submetida à técnica de microarray apresentou uma deleção do gene $Z C 3 H 12 B$ localizada no cromossomo X: 64,573,287-64,717,718. Essa deleção ainda não foi associada a qualquer tipo de distúrbio. A proteína codificada pelo gene $Z C 3 H 12 B$ pertence a uma família de proteínas que estão envolvidas na ativação das cascatas pró-inflamatórias de macrófagos (N.C.B.I). A Figura 9 demonstra o resultado do microarray para a deleção do gene ZC3H12B. A Figura 10 mostra em detalhe a deleção do gene $Z C 3 H 12 B$.

Há uma série de casos na literatura de desvio de inativação do cromossomo $\mathrm{X}$ e ocorrência de microrearranjos, em especial quando se consideram mães não afetadas de filhos afetados por, por exemplo, deficiência intelectual (Madrigal, 2007; Honda, 2010). Na amostra aqui utilizada foi escolhido como critério de inclusão que a mulher tivesse ao menos um filho não afetado por deficiência intelectual e não apresentasse relatos de deficiência intelectual na família. A ausência de associação entre aberração estrutural e o desvio de inativação nessas quatro mulheres pode ser reflexo desse critério de inclusão. 


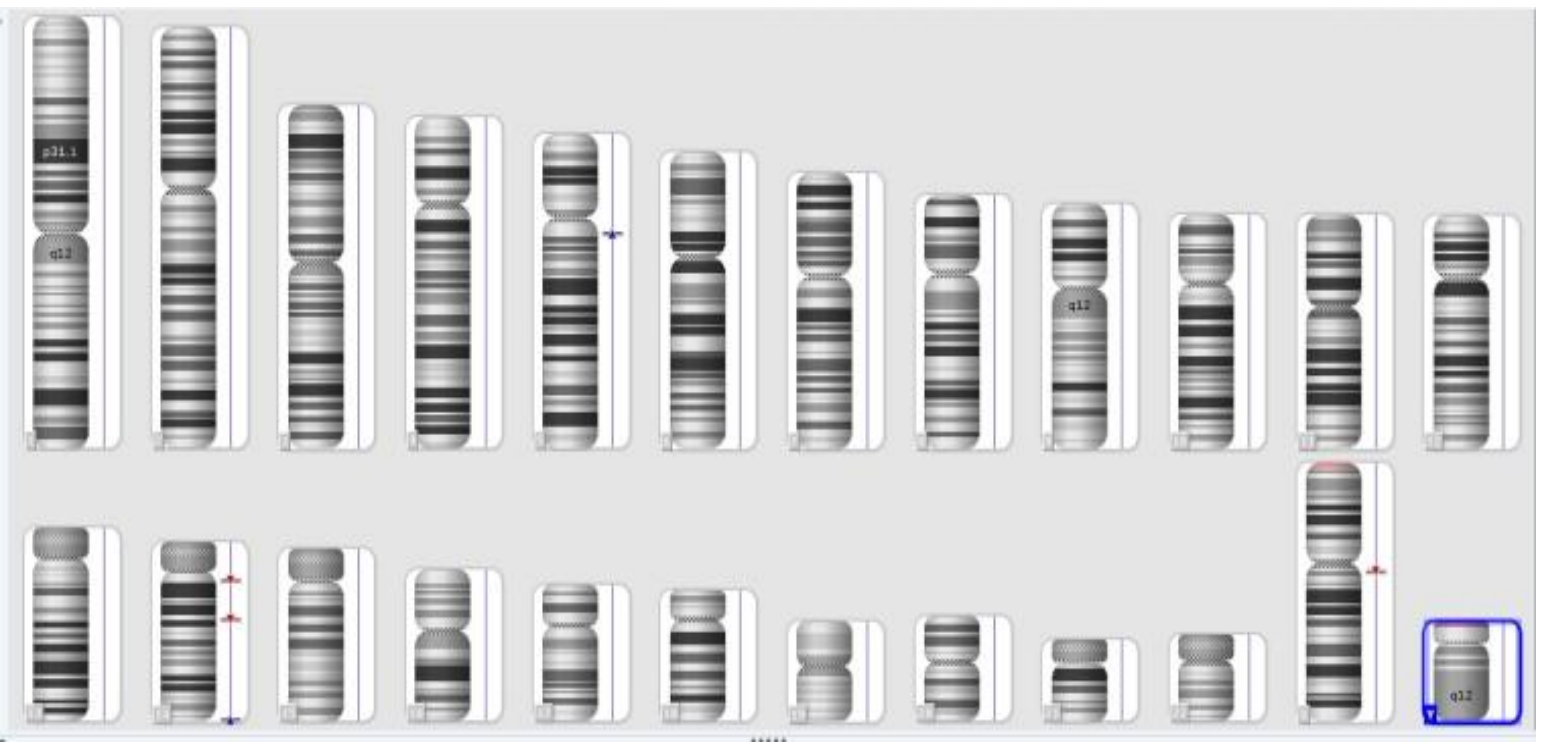

Figura 9. Resultado normal da análise cromossômica representado pelo ideograma da amostra X53, não há descrição de CNVs patogênicas, entretanto foi identificada nesta amostra uma deleção localizada em X: 64,573,287-64,717,718. 


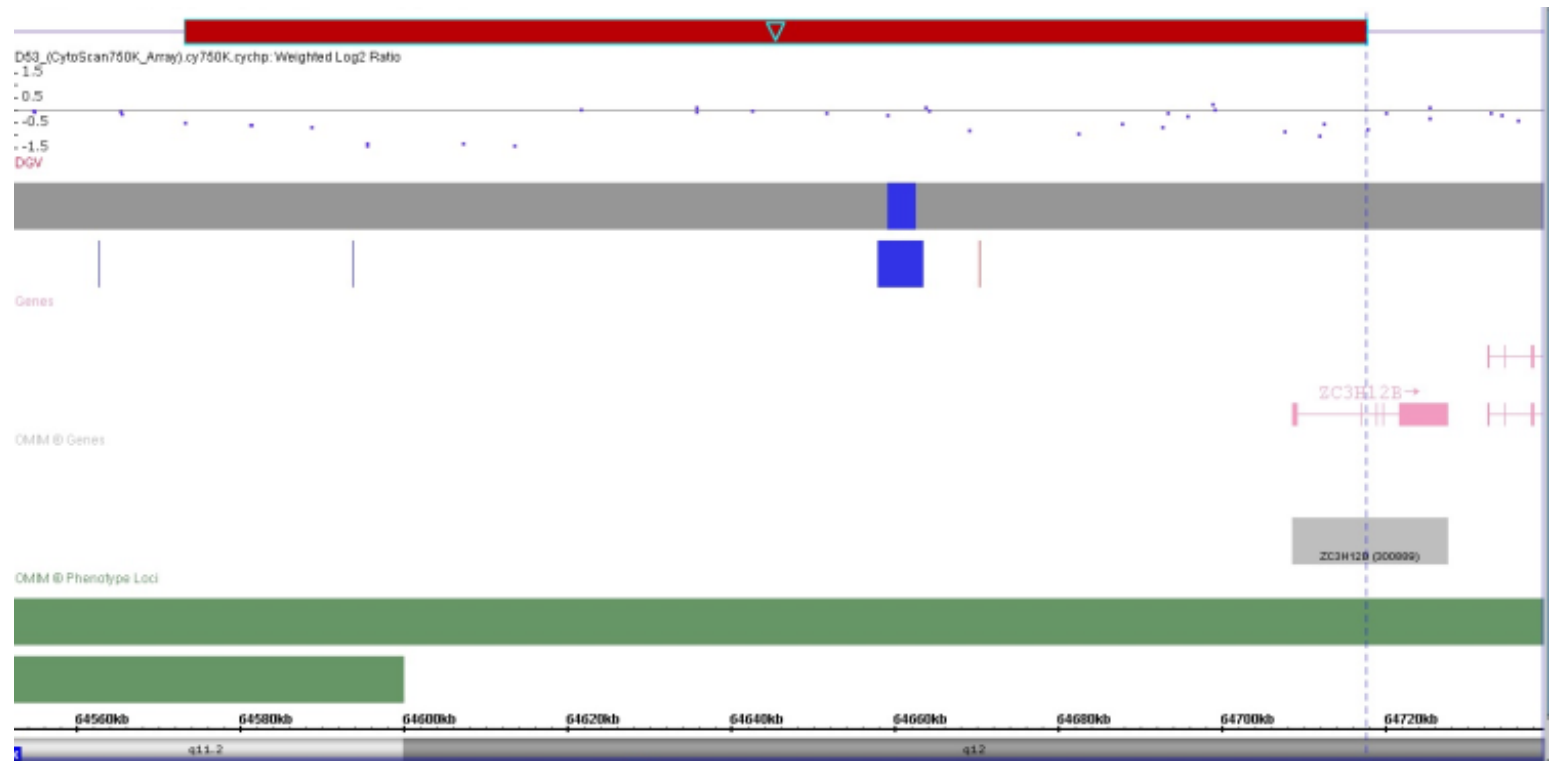

Figura 10. Resultado da deleção no cromossomo X: 64,573,287-64,717,718. A faixa azul representa a duplicação, a faixa vermelha indica a deleção e a faixa cinza representa inversão. Observa-se que a deleção do gene inclui dois primeiros êxons indicados pela cor rosa. 

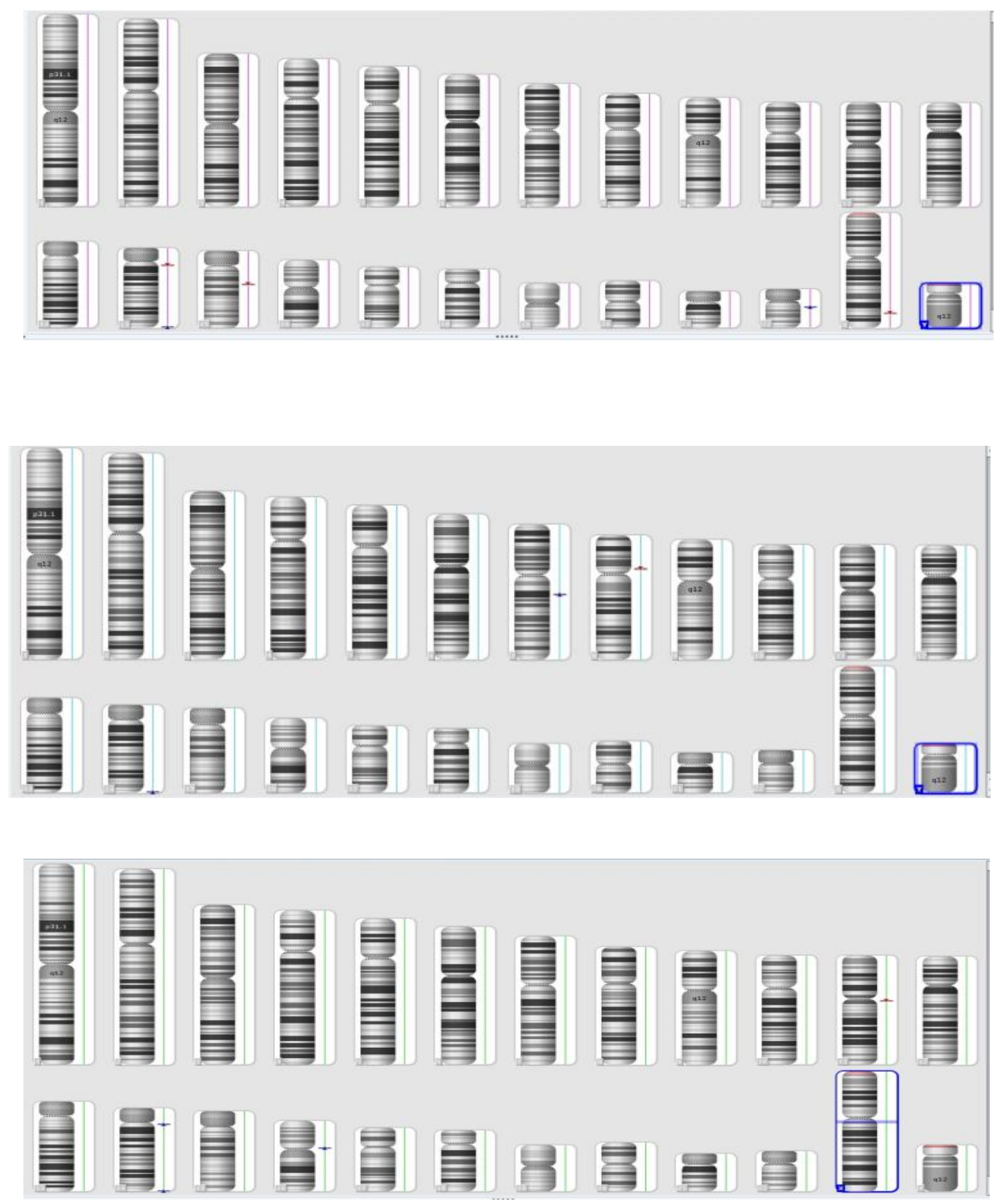

Figura 11, 12 e 13. Ideogramas dos resultados normais para as outras três amostras: X60, X84 e X99, respectivamente, as quais apresentaram desvio total de inativação do cromossomo X. 


\section{CONCLUSÃO}

i. Todas as mulheres que participaram da pesquisa se revelaram heterozigotas para a repetição polimórfica CAG presente no sítio de restrição do gene $A R$.

ii. Quatro dentre as 102 mulheres participantes apresentaram desvios extremos de inativação do cromossomo X.

iii. As quatros mulheres revelaram exame cariótipo normal e ausência de microarranjos descritos como patogênicos.

iv. Três das quatro mulheres com desvio total apresentam relato de câncer na família. 


\section{REFERÊNCIAS BIBLIOGRÁFICAS}

ALLEN, R.C; ZOGHBI, H.Y; MOSELEY, A.B; ROSENBLATT, H.M; BELMONT, J.W. (1992). Methylation of Hpall and Hhal Sites Near the Polymorphic CAG Repeat in the Human Androgen-Receptor Gene Correlates with X Chromosome Inactivation. American Journal Human Genetics v. 51, p. 1229-1239.

AMOS-LANDGRAF, J.M; COTTLE, A; PLENGE, R.M; FRIEZ, M; SCHWARTZ, C.E; LONGSHORE, J; WILLARD, H.F. (2006). X Chromosome-Inactivation Patterns of 1,005 Phenotypically Unaffected Females. American Journal of Human Genetics. v. 79, p. 493- 499 .

AUGENSTEIN, K; LANE, J.B; HORTON, A; SCHANEN, C; PERCY, A.K. (2009). Variable phenotypic expression of a MECP2 mutation in a family. J NeurodevDisord. v. 1, n. 4, p. 313.

BARR, M.L; BERTAM, E.G. (1949). A morphological distinction between neurones of the males and female, and the behaviour of the nucleolar satellite during accelerated nucleoprotein synthesis. Nature. v. 163, n. 4148, p. 676.

BARBOZA-CERDA, M.C; CAMPOS - ACEVEDO, L.D; RANGEL, R; MARTINEZ DE- VILLARREAL, L.E; DÉCTOR, M.A. (2013). A novel phenotype characterized by digital abnormalities, intelectual disability and short stature in a Mexican Family maps to Xp11.4-p11.21. Am J Med Genet A. 161A(2):237-4 .

CARVALHO, A. R. (2008). Migrantes em Brasília: os motivos, as dores e os sonhos numa perspectiva clínica. Dissertação (Mestrado). Universidade de Brasília, Instituto de Psicologia, p. 24.

CHALIGNÉ, R. EDITH HEARD. (2014). X-chromosome inactivation in development and cancer. Febs Letters. v. 588, n. 15, p. 2514-2522

COOPER, D.W; JOHNSTON, P.G. (1993). X-inactivation in marsupials and monotremes. Seminars in Developmental Biology. v.4, n. 2, p.117-128.

COQUETI, K.N. (2011). O cromossomo X e a deficiência mental no sexo masculino. Dissertação (Mestrado). Universidade de São Paulo, Instituto de Biociências, p. 45. 
CZESCHIK, C.J; BAUER, P; BUITING, K. (2013). X-linked intelectual disability type Nascimento is a clinically distinct, probably underdiagnosed entity. Orphanet $\mathbf{J}$ Rare Dis. 21;8:146.

ESCAMILLA-DEL-ARENAL, M; DA ROCHA, S.T; HEARD, E. (2011). Evolutionary diversity and developmental regulation of X-chromosome inactivation. Hum. Genet. v.130, n. 2 , p. 307-327.

FROYEN, G; BAUTERS, M; BOYLE, J; VAN ESCH, H; GOVAERTS, K; VAN BOKHOVEN, H; ROPERS. H.H; MORAINE, C; CHELLY, J; FRYNS, J.P; MARYNEN, P; GECZ, J; TURNER, G. (2007). Loss of SLC38A5 and FTSJ1 at $\mathrm{Xp} 11.23$ in three brothers with non-syndromic mental retardation due to a microdeletion in an unstable genomic region. Hum Genet, v. 121, n. 5, p. 539-47.

GANESAN, S; SILVER, D.P; GREENBERG, R.A; AVNI, D; DRAPKIN, R; MIRON, A; SAMUEL, C.MOK; RANDRIANARISON, V; BRODIE, S; RASMUSSEN, T.P; KLIMKE,A; MARRESE, C; DENG, C; FEUNTEUN, J; LIVINGSTON, D.M. BRCA1 Supports XIST RNA Concentration on the Inactive X Chromosome. Cell, v. 111, p. 393-405.

GRASSO, C.S. (2012). The mutational landscape of lethal castration-resistant prostate cancer. Nature. v. 487, p.239-243.

HELLMAN, A; CHESS, A. (2007). Gene body-specific methylation on the active X chromosome. Science. v. 315, n. 5815, p. 1141-1143.

HONDA, S; HAYASHIL, S; IMOTO, I; TOYAMA, J; OKAZAMA, H; NAKAGAWA, E; GOTO, Y; INAZAWA, J. (2010). Japanese Mental Retardation Consortium. Copynumber variations on the $\mathrm{X}$ chromosome in Japanese patients with mental retardation detected by array-based comparative genomic hybridization analysis. Journal of Human Genetics, v. 55, p. 590-599.

INSTITUTO BRASILEIRO DE GEOGRAFIA E ESTATÍSTICA. Pesquisa das Características Étnico-raciais da População: Diretoria de Pesquisas, Coordenação de População e Indicadores Sociais, 2008.

INSTITUTO BRASILEIRO DE GEOGRAFIA E ESTATÍSTICA. Censo 2010. Disponível em: < http://www.cidades.ibge.gov.br/painel/populacao>. Acesso em. 18 mar. 2015. 
JORGE, P; OLIVEIRA, B. (2013). Development and validation of a multiplex-PCR assay for X-linked intellectual disability, BMC Med Genet; 14: 80.

KATHLEEN, A; LEPPIG, C; M, Disteche. (2001). Ring X and Other Structural X Chromosome Abnormalities: X Inactivation and Phenotype. Semin Reprod Med, v. 19, n. 2, p. 147-158.

LEDERER, D. (2012). Deletion of KDM6A, a histone demethylase interacting with MLL2, in three patients with Kabuki syndrome. Am J Hum Genet, v. 90; p. 119124.

LEPPIG, K.A; SYBERT, V.P; ROSS, J.L; CUNNIFF, C; TREJO, T; RASKIND, W.H; DISTECHE, C.M. (2004). Phenotype and X inactivation in 45, X/46,X,r(X) cases. Am J Med Genet A. 128A, n. 3, p. 276-84.

LUBS, H. A; STEVERSON, R.E. (2012). Fragile X and X-linked intelectual disability: four decades of Discovery. American Journal of Human Genetics, v. 90, p. 579590.

MADRIGAL, I; RODRIGUEZ - REVENGA, L; ARMENGOL, L. (2007). X-chromosome tiling path array detection of copy number variants in patients with chromosome $\mathrm{X}$ linked mental retardation. BMC Genomics; 8: 443.

MIYAKE, N. (2012). KDM6A point mutations cause Kabuki syndrome. Hum Mutat, n. 34, p.108-110.

NASCIMENTO, D.M; OTTO, P.A; DE BROUWER, A.P ;VIANNA - MORGANTE, A.M. (2006). UBE2A, which encodes a ubiquitin-conjugating enzyme, is mutated in a novel X-linked mental retardation syndrome. Am. J. Hum. Genet, v. 79, n. 3, 549-55.

NATIONAL Center for Biotechnology Information. Disponível em: <http://www.ncbi.nlm.nih.gov/IEB/Research/Acembly/av.cgi?db=human\&q=ZC3H1 2B>. Acesso em: jan 2015.

OHNO, S; HAUSCHKA, T.S. (1960). Allocycly of the X-chromosome in tumors and normal tissues. Cancer Res., v. 20, p. 541-545.

OHNO, S. (1969). Evolution of sex chromosomes in mammals. Annu. Rev. Genet. n. 3, p. 495-524. 
OKAMOTO, I; PATRAT, C; THÉPOT, D; PEYNOT,N; FAUQUE, P. (2011). Eutherian mammals use diverse strateges to initiate $\mathrm{X}$-chromosome inactivation during development. Nature, v. 472, n. 7343, p. 370-374.

ROBINSON, W.P; BEEVER, C; BROWN, C.J; STEPHENSON, M.D. (2001). Skewed X inactivation and recurrent spontaneous abortion. Semin Reprod Med., v. 19, n. 2, p. $175-81$.

ROOMAN, R.P; VAN DRIESSCHE, K; DU CAJU, M.V. (2012). Growth and ovarian function in girls with 48, XXXX Karyotype-patient report and review of the literature. J Pediatr Endocrinol Metab. 15(7):1051-5.

ROPERS, H. H. (2010). Genetics of early onset cognitive impairment. Annu Rev Genom Hum Genet.

SCHERER, S.W; LEE, C; BIRNEY, E; ALTSHULER, D.M; EICHLER, E.E; CARTER, N.P; HURLES, M.E; FEUK,L. (2007). Challenges and standards in integrating surveys of structural variation. Nat. Genet., n. 39, S7-S15.

SHARMAN, G. B. (1971). Late DNA replication in the paternally derived X chromossome of female kangaroos. Nature.

SHEVCHENKO, A.I; ZAKHAROVA, I.S. (2013). The Evolutionary Pathway of X Chromosome Inactivation in Mammals. Acta Naturae. Apr;5(2):40-53.

SKUSE, D.H. (2005). X-linked genes and mental functioning. Hum Mol Genet., n. 14 (suppl 1): R27-R32.

TARPEY, P.S; SMITH, R; PLEASANCE, E; WHIBLEY, A; EDKINS, S; HARDY, C; O’MEARA, S; LATIMER, C; DICKS, E; MENZIES, A; STEPHENS, P; BLOW, M; GREENMAM, C; XUE, Y; TYLER - SMITH, C; THOMPSON, D; GRAY, K; MIRONENKO, T; TURNER, R; TURRELL, K; VARIAN, J; WEST, S; WIDAA, S; WRAY, P; TEAGUE, J; BUTLER, A; JENKINSON, A; JIA, M; RICHARDSON, BROUWER, A.P; VAN BOKHOVEN, H; COX, J; LUO, Y; MALLYA, U; MONN, J; PARNAU, J; MOHAMMED, S; TOLMIE, J.L; SHOUBRIDGE, C; CORBETT, M; GARDNER, A; HAAN, E; RUJIRABANJERD, S; SHAW, M; VANDELEUR, L; 
FULlSTON, T; EASTON, D.F; BOYLE, J; PARTINGTON, M; HACKETT, A; FIELD, M; SKINNER, C; STEVENSON, R.E; BOBROW, M; TURNER, G; SCHWARTZ, C.E; GECZ, J; RAYMOND, F.L; FUTREAL, P.A; STRATTON, M.R. (2009). A systematic, large-scale resequencing screen of X-chromosome coding exons in mental retardation. Nat. Genetics, v. 41, n. 5, 535-43.

WAKE, N; Takagi, N; Sasaki, M. (1976). Non-random inactivation of X chromosome in the rat yolk sac. Nature, v. 262, n. 5569, p. 580-581.

WHIBLEY, A.C; PLAGNOL, V; TARPEY, P.S; ABIDI, F; FULLSTON, T; CHOMA, M.K; BOUCHER, C.A; SHEPHERD, L; WILLATT, L; PARKIN, G; SMITH, R; FUTREAL, P.A; SHAW, M; BOYLE, J; LICATA, A; SKINNER, C; STEVENSON, R.E; TURNER, G; FIELD, M; HACKETT, A; SCHWARTZ, C.E; GECZ, J; STRATTON, M.R; RAYMOND, F.L. (2010). Fine-Scale Survey of X Chromosome Copy Number Variants and Indels Underlying Intellectual Disability. American Journal of Human Genetics, n. 87, p. 173-188.

VAN HAAFTEN, G. (2009). Somatic mutations of the histone H3K27 demethylase gene UTX in human cancer. Nature Genet., n. 41, p. 521-523.

ZECHNER, U. (2001) A high density of X-linked genes for general cognitive ability: a runaway process shaping human evolution. Trends Genet., n. 17, p. 697-701.

ZHANG, Y; MORALES - CASTILLO, ATAHUALPA; JIANG, MIN. (2013). Genes that escape $\mathrm{X}$-inactivation in humans have high intraspecific variability in expression, are associated with mental impairment but are not slow evolving. Mol Biol Evol. 30(12):2588-601.

ZOUET, Y; LIU, QIJI; CHEN, BINGXI; ZHANG, XIYU. (2007) Mutation in CUL4B: which encodes a member of Cullin-RING Ubiquitin Ligase Complex, Causes Xlinked mental retardation. Am J Hum Genet. 80(3):561-6. 


\section{Perfil de inativação do cromossomo $X$ e busca de genes associados à deficiência mental}

Dados Sujeito de Pesquisa:

Nome completo: Sexo: F [X]M [ ]

Data de Nascimento: Local de Nacimento:

Endereço:

Cidade: Estado:

País: CEP:

Telefones: E-mail:

Estado civil: Estado conjugal:

Escolaridade: Profissão:

Idade da menarca: anos

Data da menarca:

Tipo de menstruação: [ ] Regular [ ] Irregular

Idade da menopausa: anos

Data da menopausa:

Observação:

Uso de contraceptivos:

Data de início:

Atualmente:[ ] Não [ ] Sim Qual? Quanto tempo?

Antes da gravidez: [ ] Não se aplica [ ] Não [ ] Sim Qual? Quanto tempo?

Já sofreu alguma cirurgia? 
[ ] Não [ ] Sim, quando: Que tipo?

Já recebeu transfusão de sangue? [ ] Não [ ] Sim, quando:

Dados fenotípicos:

Classificação fenotípica (dada pelo pesquisador):

[ ] Branco [ ] Negro [ ] Ameríndio [ ] Asiático [ ] Misto

Autoclassificação fenotípica (dada pelo sujeito de pesquisa):

[ ] Branco [ ] Negro [ ]Ameríndio [ ] Asiático [ ] Misto [ ] Outro:

Ascendência Materna:

Ascendência Paterna:

Índices de saúde:

Peso (kg): Altura $(\mathrm{m})$ :

Pulso: Pressão arterial $\left(1^{\circ}\right)$ :

Pressão arterial $\left(2^{\circ}\right)$ :

Dados do pai:

Nome do Pai:

Local de Nascimento:

$N^{\circ}:$

Avó paterna:

Local de Nascimento:

$N^{\circ}:$

Avô paterno:

Local de Nascimento:

$N^{\circ}:$

\section{Dados da mãe:}

Nome da Mãe:

Local de Nascimento:

$\mathrm{N}^{\circ}$ :

Avó materna:

Local de Nascimento:

$N^{\circ}:$

Avô materno:

Local de Nascimento:

$\mathrm{N}^{\circ}:$

\section{Dados de Migração:}


Tempo da Família na comunidade:

Motivo da mudança:

Dados Familiares:

Irmãos: [ ] Homens [ ] Mulheres

Alguns deles/você são gêmeos?

Univitelinos: [ ] Homens [ ] Mulheres

Bivitelinos: [ ] Homens [ ] Mulheres

Existe doença genética na família? [ ] Não [ ] Sim Qual?

Parentesco dos afetados:

Observações:

Dados do Cônjuge:

Nome completo:

$\mathrm{N}^{\circ}$ :

Data de nascimento: Local de nascimento:

Parentesco:

Início do relacionamento: Término: I Local do início do relacionamento:

Residência atual:

Número de Filhos: Total ___ [ ] Homens [ ] Mulheres

Gêmeos: [ ] Não [ ] Sim Quantos:

Aborto:[ ] Não [ ] Sim Quantos:

Morto após o nascimento: [ ] Não [ ] Sim Quantos: 


\begin{tabular}{|c|c|c|c|c|c|c|}
\hline \multicolumn{7}{|c|}{ Fertilidade } \\
\hline Ordem da gestação & $1 \mathrm{a}$ & 2 & $3 a$ & $4 \mathrm{a}$ & 5 & $6 a$ \\
\hline Concepto & [ ]NV [ ]NM [ ]AB & [ ]NV [ ]NM [ ]AB & [ ]NV [ ]NM [ ]AB & [ ]NV [ ]NM [ ]AB & [ ]NV [ ]NM [ ]AB & [ ]NV [ ]NM [ ]AB \\
\hline Se NV, ainda vive? & [ ] Sim [ ] Não & [ ] Sim [ ] Não & [ ] Sim [ ] Não & [ ] Sim [ ] Não & [ ] Sim [ ] Não & [ ] Sim [ ] Não \\
\hline $\begin{array}{c}\text { Se não, data do } \\
\text { falecimento }\end{array}$ & 1 & 1 & 1 & 1 & 1 & I_ \\
\hline Se aborto, qual tipo? & {[] $\mathrm{N} \quad[$ ] I } & {[] $\mathrm{N} \quad[$ ] I } & {$\left[\begin{array}{ll}\mathrm{N} & {[\mathrm{l}} \\
\end{array}\right.$} & {[] $\mathrm{N} \quad[$ ] I } & {[] $\mathrm{N}$} & [ ]1 \\
\hline \multicolumn{7}{|l|}{$\begin{array}{c}\mathrm{N}^{\circ} \text { de semanas de } \\
\text { gestação }\end{array}$} \\
\hline $\begin{array}{c}\text { Peso/Altura do filho } \\
\text { no nascimento }\end{array}$ & $\mathrm{cm}$ & $\mathrm{Kg} /$ & $\mathrm{Kg} /$ & $\mathrm{Kg} /$ & $\mathrm{Kg} /$ & $\mathrm{Kg} /$ \\
\hline \multicolumn{7}{|l|}{$\begin{array}{c}\text { Aumento de peso da } \\
\text { mãe }(\mathrm{Kg})\end{array}$} \\
\hline Data do parto/aborto & _ــ & ـ & _ & 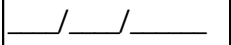 & _ـــــ & ـــ \\
\hline \multicolumn{7}{|l|}{ Lugar do parto/aborto } \\
\hline Tipo de parto & {[] $\mathrm{N} \quad[] \mathrm{C}$} & [ ] $\mathrm{N} \quad[$ ] $\mathrm{C}$ & {[] $\mathrm{N} \quad[$ ] $\mathrm{C}$} & {[] $\mathrm{N} \quad[] \mathrm{C}$} & [ ] N & [ ] N \\
\hline Gestação gemelar & [ ] Sim [ ] Não & [ ] Sim [ ] Não & [ ] Sim [ ] Não & [ ] Sim [ ] Não & [ ] Sim [ ] Não & [ ] Sim [ ] Não \\
\hline \multicolumn{7}{|l|}{$\begin{array}{c}\text { Semanas de } \\
\text { amamentação }\end{array}$} \\
\hline Hábitos da gestante & 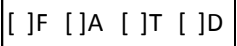 & [ ] ]F [ ] ]A [ ] ]T [ ]D & [ ] ]F [ ] ]A [ ] ] & [ ] ]F [ ]A [ ] T [ ]D & 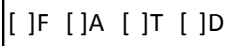 & [ ] ]F [ ]A [ ] ] [ ] ]D \\
\hline \multicolumn{7}{|l|}{ Observações } \\
\hline \multicolumn{7}{|c|}{ Concepto: NV (nascido vivo), NM (natimorto), AB (aborto) } \\
\hline \multicolumn{7}{|c|}{ Tipo de Aborto: $\mathbf{N}$ (natural), I (induzido) } \\
\hline \multicolumn{7}{|c|}{ Gestação gemelar: indicar o número de fetos } \\
\hline \multicolumn{7}{|c|}{ Hábitos da gestante: $\mathbf{F}$ (fumou), $\mathbf{A}$ (ingeriu álccol), $\mathbf{T}$ (trabalhou), $\mathbf{D}$ (esteve doente, indicar a doença) } \\
\hline Tipo de parto: $\mathbf{N}$ (norm & hal) e C (cesárea) & & & & & \\
\hline
\end{tabular}




\section{Termo de Consentimento Livre e Esclarecido - TCLE}

A Senhora está sendo convidada a participar do projeto: Perfil de inativação do cromossomo $\mathrm{X}$ em mulheres brasileiras de famílias não afetadas por deficiência intelectual e busca de genes candidatos à deficiência mental.

O objetivo desta pesquisa é estimar a incidência de desvio de inativação do cromossomo $\mathrm{X}$ em mulheres brasileiras de famílias não afetadas e comparar com o que se observa em mães de filhos (sexo masculino) com deficiência mental. Além disso, pretende-se buscar genes envolvidos na etiologia da deficiência mental e com isso entender melhor a doença assim como buscar novas metodologias de diagnóstico.

A Senhora receberá todos os esclarecimentos necessários antes e no decorrer da pesquisa e lhe asseguramos que seu nome não aparecerá, sendo mantido o mais rigoroso sigilo através da omissão de informações que permitam identificá-la.

A sua participação será através de um questionário de dados pessoais, que deverá levar aproximadamente 15 minutos para responder, e no fornecimento de material biológico na forma de sangue venoso. O procedimento de coleta de sangue será realizado com material descartável estéril por profissional habilitado, sendo que poderá ocasionar um pouco de dor local. Informamos que a Senhora pode se recusar a responder qualquer questão (ou participar de qualquer procedimento) que lhe traga constrangimento, podendo desistir de participar da pesquisa em qualquer momento sem nenhum prejuízo para a senhora. Sua participação é voluntária, isto é, não há pagamento por sua colaboração. A amostra biológica coletada ficará estocada no Laboratório de Genética da Universidade de Brasília em freezer $-20^{\circ} \mathrm{C}$. As amostras ficarão estocadas inicialmente na forma de sangue total e após a extração de DNA, na forma de DNA extraído, em caixas especificas para esse tipo de armazenamento. A amostra apresentará uma codificação alfa-numérica e só poderá ser manuseada pelos indivíduos diretamente relacionados com o projeto.

Os resultados da pesquisa serão divulgados pela Universidade de Brasília podendo ser publicados posteriormente. Os dados e materiais utilizados na pesquisa ficarão sobre a guarda do pesquisador.

Se a Senhora tiver qualquer dúvida em relação à pesquisa, por favor telefone para: Dra. Silviene F. Oliveira, na Universidade de Brasília telefone: 6131073079 no horário comercial.

Este projeto foi Aprovado pelo Comitê de Ética em Pesquisa da Faculdade de Ciências da Saúde da Universidade de Brasília. As dúvidas com relação à assinatura do TCLE ou tos do sujeito da pesquisa podem ser obtidos através do telefone: (61) 3107-1947.

Este documento foi elaborado em duas vias, uma ficará com o pesquisador responsável e a outra com o sujeito da pesquisa.

Nome / assinatura

Pesquisador Responsável

Nome e assinatura

Brasília, de de 